\title{
A Review and Evaluation of Principles used in the Estimation of Radiation Doses Associated with the Practice of Deepsea Disposal of Low- Level Radioactive Waste
}
D. A. Baker
W. L. Templeton
J. K. Soldat

September 1985

Prepared for

the U.S. Environmental Protection Agency

under a Related Services Agreement

with the U.S. Department of Energy

Contract DE-AC06-76RLO 1830

Pacific Northwest Laboratory

Operated for the U.S. Department of Energy

by Battelle Memorial Institute 
Although the research described in this article has been funded wholly or in part by the United States Environmental Protection Agency (EPA), it has not been subjected to EPA review and therefore does not necessarily reflect the views of EPA and no official endorsement should be inferred.

\title{
DISCLAIMER
}

This report was prepared as an account of work sponsored by an agency of the United States Government. Neither the United States Government nor any agency thereof, nor any of their employees, makes any warranty, express or implied, or assumes any legal liability or responsibility for the accuracy, completeness, or usefulness of any information, apparatus, product, or process disclosed, or represents that its use would not infringe privately owned rights. Reference herein to any specific commercial product, process, or service by trade name, trademark, manufacturer, or otherwise, does not necessarily constitute or imply its endorsement, recommendation, or favoring by the United States Government or any agency thereof. The views and opinions of authors expressed herein do not necessarily state or reflect those of the United States Government or any agency thereof.

\author{
PACIFIC NORTHWEST LABORATORY \\ operated by \\ BATTELLE \\ for the \\ UNITED STATES DEPARTMENT OF ENERGY \\ under Contract DE-AC06-76RLO 1830
}

\begin{tabular}{|c|c|}
\hline \multirow{2}{*}{\multicolumn{2}{|c|}{ Printed in the United States of America }} \\
\hline & \\
\hline \multicolumn{2}{|c|}{$\begin{array}{l}\text { Available from } \\
\text { National Technical Information Service }\end{array}$} \\
\hline \multirow{3}{*}{\multicolumn{2}{|c|}{$\begin{array}{c}\text { United States Department of Commerce } \\
5285 \text { Port Royal Road } \\
\text { Springfield, Virginia } 22161\end{array}$}} \\
\hline & \\
\hline & \\
\hline \multirow{2}{*}{\multicolumn{2}{|c|}{$\begin{array}{l}\text { NTIS Price Codes } \\
\text { Microfiche } A 01\end{array}$}} \\
\hline & \\
\hline \multicolumn{2}{|c|}{ Printed Copy } \\
\hline & Price \\
\hline Pages & Codes \\
\hline $001-025$ & A02 \\
\hline $026-050$ & $\mathrm{~A} 03$ \\
\hline $051-075$ & A04 \\
\hline $076-100$ & A05 \\
\hline $101-125$ & A06 \\
\hline $126-150$ & $A 07$ \\
\hline $151-175$ & $A 0 B$ \\
\hline $176-200$ & $A 09$ \\
\hline $201-225$ & A010 \\
\hline $226-250$ & A011 \\
\hline $251-275$ & A012 \\
\hline $276-300$ & $A 013$ \\
\hline
\end{tabular}


A REVIEW AND EVALUATION OF PRINCIPLES USED

IN THE ESTIMATION OF RADIATION DOSES

ASSOCIATEO WITH THE PRACTICE OF DEEPSEA

DISPOSAL OF LOW-LEVEL RADIOACTIVE WASTE

D. A. Baker

H. L. Templeton

J. K. Soldat

September 1985

Prepared for

the U.S. Environmental Protection Agency

under a Related Services Agreement

with the U.S. Department of Energy

Contract DE-ACO6-76RLO 1830

Pacific Northwest Laboratory

Richland, washington 99352 
In 1981, Pacific Northwest Laboratcry was asked by Environnental Protection Agency/Office of Radiation Programs (EPA/CRP) to review the relevant national and international guidance concerning the estimation of radiologica 1 doses delivered from the practice of deepsea disposal of radioactive waste.

This review includes the dose limitation guidance of the various national and international bodies, especially that of the International Commission on Radiologicat Protection (ICRP). Pathway modeling is discussed as well as the oceanographic models of the Internationai Atomic Energy Agency (IAEA). Included in the discussion are the recommendations of the IAEA for the definition of high-level waste, used by the London Dumping Convention (LDC) in setting limits for ocean disposal of waste. The ICRP's radiological protection system is assessed using the effective whole-body dose methodology is made.

Present models, which should continue to be improved as the research data becomes available, do provide an adequate basis for regulatory authorities to decide whether authorization for a proposed disposal site can be granted, because they provide a means of indicating whether maximum individual (critical groups) exposure limits are likely to be exceeded. However, new mocels and information are continuously being developed by the international community to compare ocean disposal to land disposal of radioactive waste and to compare one site against another. 


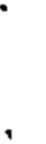

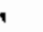

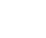




\section{ACKNOWLEDGMENTS}

We wish to express our gratitude to Robert S. Dyer, Office of Radiation Programs, Environmental Protection Agency, for his ideas, support, discussion, and assistance in this work. We also wish to thank John E. Till for his pertinent and helpful advice. 


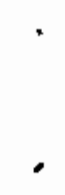




\section{CONTENTS}

SUMMAR

ACKNOWLEDGMENTS

GLOSSARY

INTRODUCTION

DOSE LIMITATIONS AS RECOMMENOEO BY VARIOUS ORGANIZATIONS

OOSE CATEGORIES. ICRP

NCRP.

WHO

U.S. GOVERHMENT

Federal Radiation Council

Environmental Protection Agency . . . . . . 7

ICRP RADIATION PROTECTION PHILOSOPHY

JUSTIFICATION

OPTIMIZATION

PATHWAY DOSE MOOELING

STEADY-STATE MODELING

TRANSIENT MODELING

SPECIFIC ACTIVITY

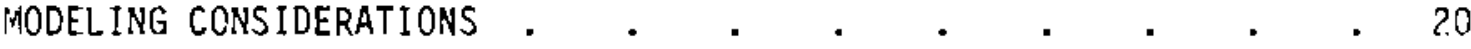

SELECTION AND IOENTIFICATION OF PARAMETER VALUES $\cdot \cdot \cdot \cdot \cdot 21$

Nature of the Released Radioactivity . . . . . . 22

Concentration Factors . . . . . . . . . . 22

Consumption Rates and Occupancy Factors . . . . . 23

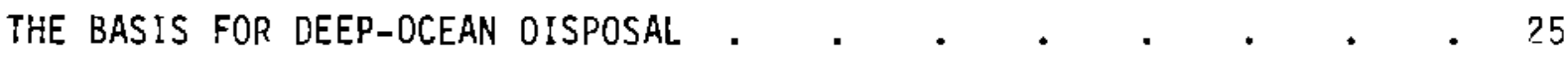

LONDON DUMPING CONVENTION RECOMMENDATIONS • • • • • • 25

RADIOLOGICAL EVALUATION OF OCEAN-OISPOSAL PRACTICES • • • 27

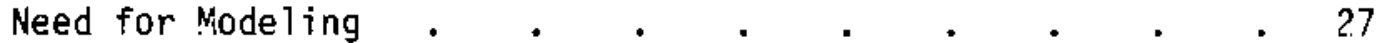

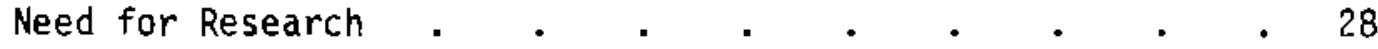

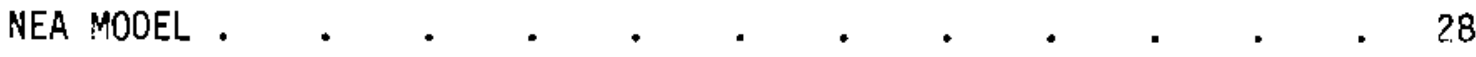

Release Model . . . . . . . . . . . 29

Marine Mode1 . . . . . . . . . . . 29

Pathway Model . . . . . . . . . . . . 29 
IAEA MODEL . . . . . . . . . . . . . . . . 30

Oceanographic Component . . . . . . . . . . . 31

Radiological Component . . . . . . . . . . . 34

PROBLEMS IN THE ASSESSMENT OF OCEAN DISPOSAL OF LOW-LEVEL WASTE • $\quad 39$

COLLECTIVE DOSE

CHOICE OF A RADIOLOGICAL PROTECTION SYSTEM . . . . . . 40

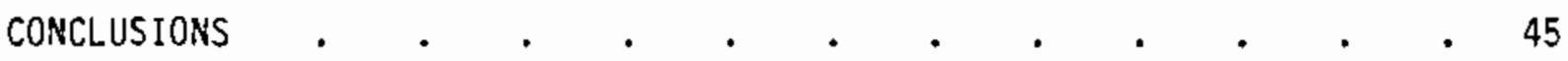

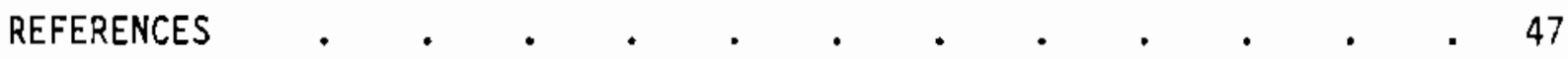




\section{FIGURES}

1 Theoretical Relationships Between Costs and Collective Dose Showing Optimum Collective Dose, $\mathrm{S}_{0}$, at Optimum Cost, $\mathrm{C}_{0}$. . 11

2 Simple Compartment Model . . . . . . . . . . . 18

\section{TABLES}

1 Current NCRP Dose Limits for Members of the Public or Occasionally Exposed Individuals . . . . . . . 5

2 Pathways and Mode of Exposure in the IAEA Radiological Basis . 35

3 Pathways and Usages Proposed by the IAEA . . . . . 37

4 Comparison of Allowable Intake by Individua] Members of the Public for Selected Radionuclides . . . . . . . . 43 
GLOSSARY

This list provides some understanding of a selection of specialized terms used in this report.

Absorbed dose - The amount of energy in the form of ionizing radiation absorbed in a unit mass of matter. The unit is the gray $(G)=1$ joule $/ \mathrm{kg}$ $=100 \mathrm{rad}$.

Activity - A measure of the rate at which a material is emitting nuclear radiations; radioactivity usually given in terms of the number of nuclear disintegrations occurring in a given quantity of water over a period of time. The unit of activity is the becquerel $(\mathrm{Bq})=1$ disintegration $/ \mathrm{s}=$ 27 picocurie.

Acute - Pertaining to a short and sharp course. An acute dose would be that delivered over a short time period.

Adsorption - The process of attachment onto particle surfaces.

ALI - Annual Limit of Intake. The limiting intake in Bq that a radiation worker may ingest without exceeding the effective dose limit of $50 \mathrm{~m} / \mathrm{S} / \mathrm{yr}$ (5 rem/yr).

Alpha radiation - An emission of particles (helium nuclei) from a material undergoing nuclear transformation (decay); the particles have a nuclear mass number of four and a charge of plus two.

Average individual - An individual of the general public whose habits are average for the general population.

Becquerel - International System (SI) unit of activity (1 Bq = 1 disintegration $/ \mathrm{s}=\hat{2} 7 \mathrm{picocurie}$ ).

Benthic - Pertaining to biota living on or in the sea-bed.

Beta radiation - Charged particles (electrons and positrons) emitted from the nucleus of atoms undergoing nuclear transformation (beta decay).

Biogenic - Pertaining to material originating from biological processes.

Biota - Plant and animal life; the living things of a region.

Bioturbation - Mixing of surface sediments by animals.

Chronic - Pertaining to a long duration. A chronic dose would be that which is delivered over a long time period.

Collective dose equivalent - (Often referred to as collective dose or population dose.) The summation of the radiation dose (in remi or SV) received by all individuals in a population group. It is principally applied to whole-body dose where it has units of man-rem, perscn-rem, or man-Sv. 
Committed dose equivalent - The dose equivalent that will be delivered over 50 years, representing a working lifetime, following an intake of radioactive material.

Compiexation - The formation of a complex compound that is a type of compound in which a part of the molecular binding is of the coordinate type.

Concentration factor - Ratio of concentration cf an element or radioruclide in an aquatic plant or animal to that of the surrounding water at equilibrium.

Critical group - For a given source or group of sources, the group of members of the public whose exposure is reasonably homogeneous and is typical of individuals receiving the highest dose.

Critical pathway(s) - The pathway(s) through which the critical group receives their radiation dose. Those paths by which an individual or poputation receives the highest dose.

Curie ( $C \mathrm{i}$ ) - Unit of activity defined as the amount of a radioactive material that has an activity of $3.7 \times 10^{10}$ disintegrations/s. Replaced by the new SI standard unit: becquerel $=1$ disintegration $/ \mathrm{s}=27$ picocurie.

Decay chain - The sequence of radioactive disintegrations in succession from one nuclide to another until a stable daughter is reached.

Detriment - The mathematical expectation of harm which is detemined by taking into account the severity of an effect and the probability of its occurrence.

Dose commitment - The integrated dose that results from external exposure to, or an intake of radioactive material when dose is evaluated from the beginning of exposure or intake to a later time (usually 50 years). A?so used for the long-term integrated cose to which people are considered committed because radioactive material has been released to the environment.

Dose equivalent - The product of absorbed dose, quality factors, dose distribution factor, and other necessary modifying factors. The unit is the sievert $(S V)=100$ rem.

Dose factor - A number which relates the dose to an intake of a radionuclide over some time period, usually a year; e.g., rem per Ci.

Disposal - The planned release or placement of waste in a manner that precludes recovery; dumping (as used by the AIEA and related international bodies).

Effective dose equivalent - The sum of the product of mean dose equivalents for an organ (tissue) and their respective weighting factors as defined in ICP.P-26.

Exposure - The condition of being made subject to the action of radiation or agents such as chemicals. 
Extreme near-field - That part of the benthic boundary layer in the vicinity of a release. It is essentially the region where the model for predicting near-field concentration breaks down due to the difference between the mixing rates in the benthic boundary layer and in the over-lying water. In practice, this region could be of the order of 100-m thick and perhaps $30 \mathrm{~km}$ in radius. (IAEA 1984)

Far-field - Consists of the rest of the ocean, outside the near-field. (IAEA 1984)

Food chain - A number of organisms forming a feeding series through which energy is passed.

Gamma radiation - Electromagnetic energy emitted in the process of a nuclear transition.

General population - Group or population not employed in occupations dealing with radioactive materials.

Generic - Pertaining to the general characteristics of a number of sites.

Gray (Gy) - International System (SI) unit for absorbed dose ( $1 \mathrm{~Gy}=1 \mathrm{~J} / \mathrm{kg}=$ $100 \mathrm{rad}$ ).

Half-life - The time required for the activity of a radionuclide to decay to half its value; used as a measure of persistence of radioactive materials.

HLW - High-level waste. In general that nuclear waste that is made up of fission products and actinides resulting from reprocessing spent fuel from nuclear reactors. For purposes of ocean disposal the definition of the London Dumping Commission is applicable. See page 25.

Hydrospheric dispersion factor - The ratio of the concentration of a material in water at a location to the release rate of the material into the water at the point of origin. This factor is usually derived from oceanographic models. Analogous to the atmospheric dispersion factor $(x / q)$ for estimating concentrations of a material in air downwind from its release point.

Individual member of the pubiic - Individual member of the general population. Not a worker in a radiation industry.

Justification - A concept of the ICRP in which no practice shall be adopted unless its introduction produces a positive net benefit. Justification is concerned with the original practice which generated the waste, such as nuclear power, weapons, medical isotopic waste, but not the disposal of the waste.

Life-saving dose - Dose from radioactive material judged to be acceptable to an individual involved in saving the lives of others. 
Maximum individual (maximally exposed individual) - An individual of the general public whose locations and habits tend to maximize his radiation dose, resulting in a dose higher than that received by other individuals in the general population. See Critical Group.

Model (mathematical) - Representation of a physical, chemical, or biolcgical system by mathematical expressions designed to aid in predicting the behavior of the system under specified conditions.

MPC - Maximum permissible concentration. The average concentration of a radionuclide in air (MPCa) or water (MPCW) to which a worker or member of the general population may be continuously exposed without exceeding an established standard of radiation dose limitation.

MPRI - Maximum permissible rates of intake of a radionuclide. Product of MPC and annual consumption rate. See MPC.

Near-field - The region in the vicinity of the release in which the concentration is significantly greater than the ocean basin average. Its size is variable but is usually less than $10 \%$ of the volume of the ocean basin, and may be very much less for very long-lived contaminants. (IAEA 1984)

Nonstochastic effects - Those effects for which the severity of the effect varies with the dose.

Nuclide - A species of atom having a specific mass, atomic number and nuclear energy state.

Optimization - A concept of the ICRP in which all exposures shall be kept as low as reasonably achievable (ALARA), economic and social factors being taken into account.

OTHL - Other than high level [waste]. Nuclear waste that is not defined as high level by the London Dumping Commission. See Page 25.

Quality factor (Q) - The factor by which the absorbed dose (rad or Gray) is multiplied to obtain a quantity that expresses the effectiveness of the absorbed dose on a common scale for all ionizing radiation. In practice, $Q$ is taken as unity for $x$-rays, gamma rays, and beta particles. See Dose equivalent.

Radiation (ionizing) - Particles and electromagnetic energy emitted by nuclear transformations that are capable of producing ions when interacting with matter; gamma rays and alpha and beta particles are examples.

Radioactivity - See Activity.

Radionuclide - Any nuclide that is radioactive.

Radon daughters - The members of the decay chain of radon-222: polonium-218, lead-214, bithmuth-214, polonium-214, lead-210, bithmuth-210, polonium-210, and 1ead-206 (stable). 
Radwaste - Waste that contains radioactive materials.

Release limit - Number against which the concentration of radioactive material released to the environment from a facility or practice is controlled; usually derived from a dose limit for persons in the environment by considering the environmental behavior of the released material and habits of persons considered to be at risk.

Rem - Unit of dose equivalent. The absorbed dose of ionizing radiation modified by the quality factor and sometimes other factors that result in the same biological effect as one rad of radiation; one rem equals one rad for $X$ or gamma radiation. Standard unit of dose equivaient in United States governmental regulations. See Dose equivalent, Sievert, Quality factor, Gray.

Residence time - A time characteristic of the length of time spent by a substance in an oceanic system.

Scavenging - The removal of chemical elements from the ocean by their incorporation into or attachment onto surfaces of particles or their ingestion by living organisms.

Sediment - A solid material that is not in solution and is either distributed throughout the liquid (suspended) or has settled out of the liquid.

Sievert (Sv) - International System (SI) unit of dose equivalent (1 Sv = 100 rem). The standard unit for dose equivalent in European literature and regulations.

Site specific - Pertaining to the characteristics of one particular site.

Somatic Effects - Those effects of radiation that are expressed during the iffetime of an individual but are not passed on to future generations.

Specific activity - As used in this report, the ratio of the concentration of an isotope in a particular media to the concentration of its stable analog in that media. Also the activity of an isotope per unit mass of compound, element, or radioactive nuclide. As used by the IAEA in their high-level waste definition, the ratio of the activity of a material disposed of into the sea to that of its mass in $\mathrm{Bq} / \mathrm{kg}$.

Stochastic effects - Those effects for which the probability of them occurring, rather than their severity, are regarded as a function of dose.

Tera $-(T)-10^{12}$ as in $T B q=10^{12} \mathrm{~Bq}$.

Tonne $(t)$ - Metric ton = 1 megagram $=1000 \mathrm{kilogram}$.

Transuranic - Pertains to elements having atomic numbers greater than that of uranium (92); all are radioactive and members of the actinide group. 
Tritium - Isotope of hydrogen with atomic mass number of three.

Weighted whole-body dose - Effective dose equivalent to the body as a whole. See Effective dose equivalent.

Weighting factor $\left(W_{T}\right)$ - A weighting factor representing the proportion of the stochastic risk resulting from tissue $(T)$ to the total risk, when the whole body is irradiated uniformly (ICRP-26). See Effective dose equivalent. 


\section{A REVIEW AND EVALUATION OF PRINCIPLES USED IN THE ESTIMATION OF RADIATION DOSES ASSOCIATED WITH THE PRACTICE OF DEEPSEA \\ DISPOSAL OF LOW-LEVEL RADIOACTIVE WASTE}

\section{INTRODUCTION}

The selection of a specific methodology for the assessment of the risks of ocean disposal of other than high-level radioactive waste (OTHLW) must be preceded by an examination of the need for this mode of waste disposal. Assuming that such disposal would be permitted and licensed by a governmental agency, some limitation must be placed on the quantities to be disposed, the location of the disposal site, the waste matrix material, the kinds of monitoring to be performed, and the types of containers. In the United States, the agency assigned the responsibility for developing such limitations and guidance is the Environmental Protection Agency (EPA). However, any regulations and criteria the EPA promulgates should be at least as restrictive as the recommendations of international bodies such as the International Atcmic Energy Agency (IAEA) and the Nuclear Energy Agency (NEA). They should also be in accord with provisions contained in the London Dumping Convention (LDC) that cover the practice of ocean disposal of wastes, including those that are radioactive.

The U.S. guidance must address the sea disposal of wastes by any commercial or governmental entity within the U.S. territorial waters and Exclusive Economic Zone (out to 200 miles from the coast 1 ine) to ensure protection of the U.S. population and of the contiguous marine environment. In addition, the U.S. guidance must cover disposal by U.S. entities in international waters, since the United States is a signatory to the LDC.

In this report we discuss the radiological protection considerations necessary for the disposal of low-level radioactive waste that could detrimentally affect populations on a national and international scale. The applicable dose limitations, which have been recommended for various practices by the International Commission on Radiological Protection (ICRP), the National Council on Radiation Protection and Measurements (NCPP), and the EPA have been 
identified. Some recent conclusions from the World Health Organization (WHO) concerning waste disposal have been summarized.

This report primarily considers the current :CRP-IAEA philosophy concerning dose assessment and the modeling of dse pathwavs to individuals and populations from release of radioactive materials in the deep ocean. The present IAEA release 1 imits for ocean disposal of low-level radioactive waste are discussed, along with models proposed by NEA and IAEA. Finally, some of the inadeouacies of the recent ICRP methodology for calcuiating dose is presented. 


\section{DOSE LIMITATIONS AS RECOMMENDED BY VARIOUS ORGANIZATIONS}

The following discussion provides a summary of dose categories and presents the pertinent radiation guidance that has been developed over the years by various national and international bodies. It concentrates primarily on the radiation standards set for the general population; standards for radiation workers will not be covered.

\section{DOSE CATEGORIES}

Radiation doses (a) can be calculated for individuals in a "critical group" and for populations. In order to assess the dose received by an exposed population in dose equivalent terms, use is made of the collective dose equivalent. This collective dose can be obtained by integration of the ranges of dose rates within the population or the population group. In actual practice, this collective dose is usually derived by multiplying the average or per capita dose equivalent by the number of individuals of a sub-group in the population. In some instances, assessment of collective dose can be simplified, often avoiding the need to identify and assess the separate individual doses. For example, in a food-chain pathway it is sufficient to know only the total collective consumption of marine organisms, not the individual consumption rates. However, in a geographically extensive pathway, such as fish consumption, it will be necessary to group the total catches and to weight them by their concentrations of radioactivity. The tatter will generaily vary with distance from the point of release.

The collective dose rate will vary as a function of time. The total collective dose equivalent commitment from a particular source can be obtained by integrating the collective dose equivalent rate. This collective dose equivalent commitment is required for the justification or optimization of different choices of waste management practices. The collective quantities are frequently expressed as man-rem (or man-Sv) to distinguish them from individual doses.

(a) The term "dose" in this report should be interpreted to mean the sum of the internal and external dose equivalents unless otherwise indicated. 
ICRP

The International Commission on Radiological Protection (ICRP) has recommended radiation protection standards for consideration by their member countries. Their first standard, issued in 1959 (ICRP 1959) as well as a later one issued in 1965 (ICRP 1965), set the dose-rate limit to the whole body of a member of the public at $500 \mathrm{mrem} / \mathrm{yr}(5 \mathrm{mSv} / \mathrm{yr})$. This same limit was also stipulated for the gonads and red bone marrow. A dose-rate limit of $3 \mathrm{rem} / \mathrm{yr}$ (30 mSv/yr) was stipulated for skin, bone and thyroid. However, the limit was set at $1.5 \mathrm{rem} / \mathrm{yr}$ ( $15 \mathrm{mSv} / \mathrm{yr}$ ) for thyroids of children up to age 16 . Later, in 1977, the ICRP revised their dose recommendations on the basis of a new concept of (weighted) effective whole-body dose (ICRP 1977).

Recommendations were made for "stochastic" and "nonstochastic" effects. Stochastic effects were defined as those for which the probability of an effect occurring, rather than its severity, is regarded as a function of dose, without threshoid. On the other hand, nonstochastic effects were defined as those for which the severity of the effect varies with dose and for which a threshold may occur.

The ICRP regards hereditary effects and somatic effects, primarily cancer, as stochastic. Nonstochastic effects are specific to particular tissues, such as lens cataracts, nonmalignant skin damage, depletion of bone marrow, and gonadal cell damage, which may cause infertility.

In their 1977 recommendations, the ICRP went on to define two types of members of the general population: critical groups and average members of the population. A typical member of the critical group would closely resemble the "maximum individual" as used in this country. The average member of the population would correspond to our "average individual" in U.S. nomenclature or the European "per caput." The 1977 ICRP dose recommendations (pp. 23-25) were as follows:

Stochastic:

Critical groups $500 \mathrm{mrem} / \mathrm{yr}$ ( $5 \mathrm{mSv} / \mathrm{yr}$ ) (whole body) Nons tochastic:

Any member of public

$5 \mathrm{rem} / \mathrm{yr}(5 \mathrm{C} \mathrm{mSv} / \mathrm{yr})$ 
The above stochastic $1 \mathrm{imit}$ of $500 \mathrm{mrem} / \mathrm{yr}(5 \mathrm{mSv} / \mathrm{yr}$ ) to individual members of the public is likely to result in average dose equivalents of less than $50 \mathrm{mrem} / \mathrm{yr}(0.5 \mathrm{mSv} / \mathrm{yr})$ provided that practices exposing the public are few and cause little exposure outside the critical group.

NCRP

More recentiy, the National Council on Radiation Protection and Measurements (NCRP) issued limits for maximum radiological dose in the United States (NCRP 1975). Their recommended annual dose 1 imit for an occasionally exposed individual member of the general public was 500 mrem $(5 \mathrm{mSv}$ ). An average. annual dose of $170 \mathrm{mrem}(1.7 \mathrm{mSv})$ for the general public was stipulated. This limit was to apply to both genetic and somatic doses.

Table 1 lists the current NCRP dose 1 imits that are in effect for the United States.

TABLE 1. Current NCRP Dose Limits for Members of the Public or Occasionally Exposed Individuals (NCRP 1975, p. 34)

Individual Dose Limits

Occasionally Exposed individuals (Public) 0.5 rem in any one year Students

0.1 rem in any one year

Population Dose Limits

0.17 rem average per year

Emergency Dose Limits - Life Saving

Individual (older than 45 if possible) 100 rem

Hands and Forearms

200 rem, additional

(300 rem tota 1 )

Emergency Dose Limits - Less Urgent

Individua 1

Hands and Forearms

25 rem

100 rem total

Family of Radioactive Patients

Individual (under age 45)

Individual (over age 45)

0.5 rem in any one year

5 rem in any one year 
$\underline{\mathrm{WHO}}$

Historically, the World Health Organization (WHO) has accepted the ICRP dose 1 imits and philosophy. A recent WHO working group (WHO 1978) agreed that the basic principle to be used in formulating radiation protection regulations is the ICRP recommendation that all radiation exposures should be kept as low as readily [sic] achievable, with economic and social considerations being taken into account. With regard to the dumping of waste into the oceans, the working group recognized that current dumping levels represent only a minute fraction of the maximum amounts permitted by the IAEA (IAEA 1975). However, they recommended that studies of sea disposal, as well as other methods of waste disposal, be continued, and they called upon the IAEA to accelerate the acceptance by the member states of the IAEA recommendations and procedures, as specified in the London Dumping Convention (WHO 1978, p. 33). In these studies, the working group stressed that attention should be paid to the various exposure routes to humans rather than to possible effects on aquatic populations. Although they found no evidence that previous releases into the sea have been harmful to anyone, the group cautioned that prudence dictates that the exposure routes leading to man and to accumulation in marine organisms should be kept under close review (wH0 1978, p. 34 ).

U.S. GOVERNMENT

Federal Radiation Council

The U.S. Federal Radiation Council (FRC) was established in 1960 to provide guidance to the President of the United States in radiation matters. The FRC established and promulgated radiation standards that were not to be exceeded (without formal justification) by federa? agencies. In their first report (U.S. FRC 1960), the council set limits for external exposure of the total body; viz., $0.5 \mathrm{rem} / \mathrm{yr}(5 \mathrm{mSv} / \mathrm{yr}$ ) to the individual and $5 \mathrm{rem}(50 \mathrm{mSv}$ ) per $30 \mathrm{yr}$ (equal to $0.17 \mathrm{rem} / \mathrm{yr}(1.7 \mathrm{mSv} / \mathrm{yr}$ )) to the average individual of a suitable sample of the exposed population. In their second report (U.S. FRC 1961), the council recommended that exposure of bone and thyroid from internally deposited radionuclides be 1 imited to $1.5 \mathrm{rem} / \mathrm{yr}$ (15 mSv/yr) for the 
individual and $0.5 \mathrm{rem} / \mathrm{yr}(5 \mathrm{mSv} / \mathrm{yr})$ for a suitable sample of the population. By presidential order the authority of the FRC was transferred to the EPA after its formation in 1970 .

Envi ronmental Protection Agency

The EPA has promulgated dose limits for any member of the general public from the uranium fuel cycle (40 CFR 190) and geologic disposal of high-level wastes (40 CFR 191). These limits state that the total annual dose from all aspects of the uranium fuel cycle shall not be greater than 25 mrem $(0.25 \mathrm{mSv})$ to the whole body, $75 \mathrm{mrem}(0.75 \mathrm{mSv})$ to the thyroid, and 25 mrem $(0.25 \mathrm{mSv}$ ) to any other organ. It should be noted that doses received from mining operations, waste disposal, and associated transportation in support of those operations are not included when determining compliance to these limits. In addition, the dose from radon daughters is not included in this regulation, but is to be addressed separately. 



\section{ICRP RADIATION PROTECTION PHILOSOPHY}

The ICRP radiation protection philosophy is based on three primary guiding principles:

- Justification: No practice, such as power production, weapons, medical isotopes, etc. shali be adopted unless it produces a positive net benefit;

- Optimization: All exposures shall be kept as low as reasonably achievable (ALARA), economic and social factors being taken into account; and

- Compliance: The dose equivalent to individuals shall not exceed the limits recommended for the appropriate circumstances by the Commission.

Taken together, these constitute what is known as the ICRP dose-limitation system (ICRP 1973, ICRP 1977):

The following presentation describes the steps necessary to fulfill the above requirements with respect to the disposal of low-level radioactive waste into the sea.

JUSTIFICATION

The ICRP considers that the principle of justification is not amenable to formal analysis because the establishment of "net benefit" from a practice or operation, such as power production, weapons, medical isotopes, etc., requires the assessment of many broad issues. These may include economic, social, military, scientific, and political considerations. However, the ICRP regards such analysis as not being especially necessary since the practice being considered will have al ready been selected and so justified by a consensus of the issues.

OPTIMIZATION

The idea that all exposures be kept "as low as practicable" or "as low as reasonably achievable" has long been a part of ICRP's recommendations. In this country the concept has been advocated by the NCRP and has been an 
important objective for the EPA and NRC. In 1973, the ICRP first addressed the practical implications of such a recommendation (ICRP 1973). Later the ICRP stated that the optimization condition will be fulfilled when the level of exposure is such that the increase in the cost of protection per unit dose equivalent balances the reduction of detriment per unit dose equivalent (ICRP 1977). The ICRP then went on to describe a methodology that can be used to assist in determining optimization. This formalism is described below.

The ICRP provides a general equation to describe the net benefit, $B$, to be derived from a practice or operation concerned with radioactive materials (ICRP 1977):

$$
B=V-(P+X+Y)
$$

where $V=$ gross benefit of operation or practice

$P=$ basic production costs

$X=$ cost of achieving a selected level of protection

$Y=$ cost of the detriment involved in the cperation or practice.

Optimization is achieved when the net benefit is maximized with respect to the costs associated with the level of radiation protection. Let $X$ and $Y$ be functions of the collective dose, $S$, and assume that the gross benefit, $V$, and production costs, $P$, are independent of $S$. Then on differentiating Equation (1) with respect to $S$, we arrive at

$$
(d X / d S)_{S_{0}}+(d Y / d S)_{S_{0}}=0
$$

where $S_{0}=$ optimum level of collective dose $\left(d B / d S_{0}=0\right)$. Figure 1 shows this relationship.

Since it is not usually practical to consider infinitesimal changes in costs and collective doses, Equation (2) may be written in terms of finite increments.

$$
(\Delta X / \Delta S)_{S_{0}}+(\Delta Y / \Delta S)_{S_{0}}=0
$$




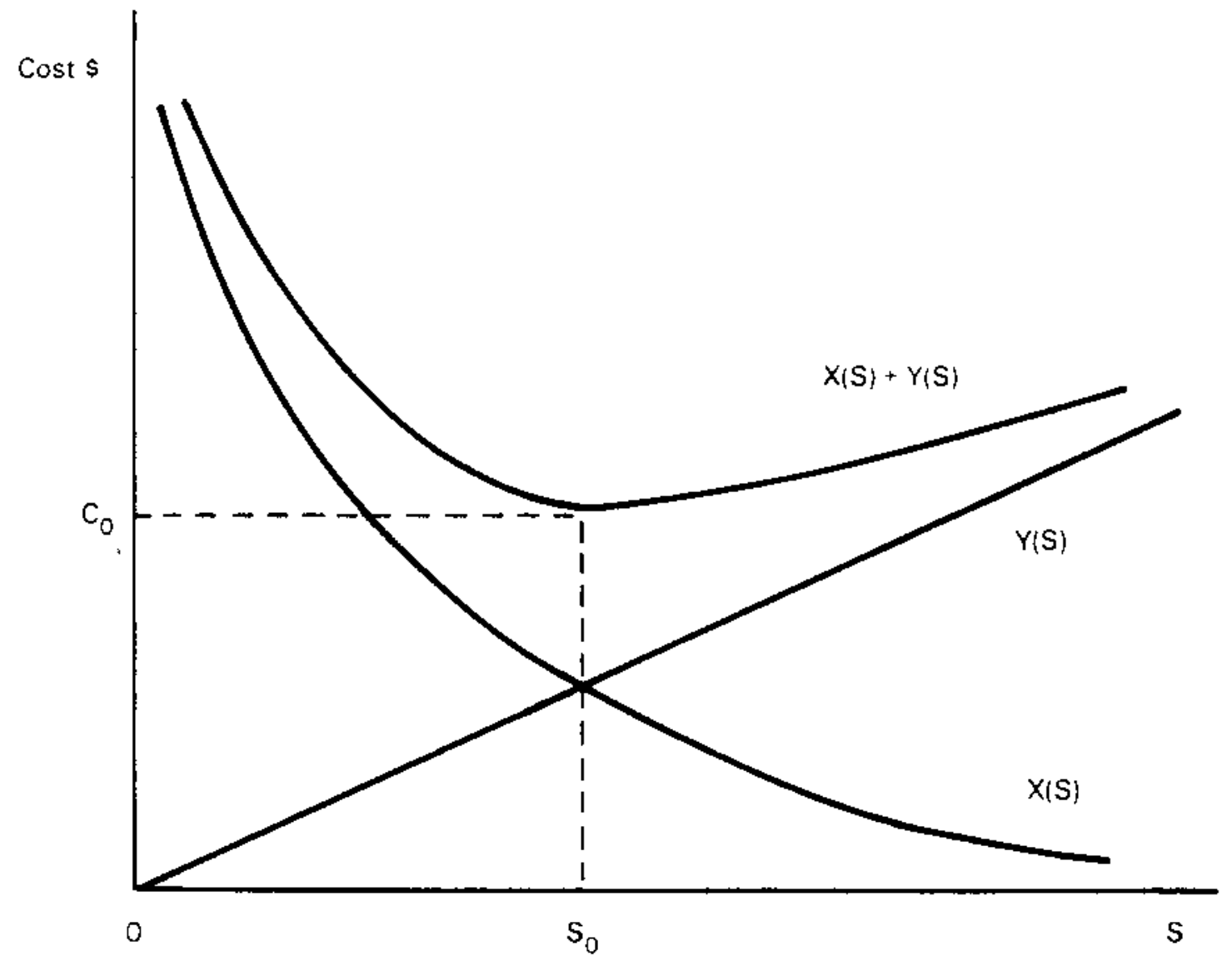

FIGURE 1. TheoreticaT Relationships Between Costs and Collective Dose Showing Optimum Collective Dose, $S_{0}$, at Optimum Cost, $\mathrm{C}_{0}$

Then by cancelling the $\Delta S$ in the denominators of Equation (3), we can write:

$$
\Delta X+\Delta Y=0
$$

The result can be obtained by a simple inspection of tables of cost values, but with discrete options it is very unilikely that the incremental costs can be exactly matched. The optimum control option will be defined when $\Delta X+\Delta Y$ is closest to zero for a set of options. It should be emphasized that while it is easy to specify mathematically a procedure for optimization, it is exceedingly difficult to apply this formalism in practice. Examples of the application of these equations may be found in the recent IAEA proceedings (IAEA 1979b). 



\section{PATHWAY DOSE MDDELING}

To determine the appropriate release limit to set for a specific practice or operation, the various pathways leading to man must be analyzed to determine those that could lead to doses exceeding the limit or that lead to the highest exposure: These are often referred to as critical pathways and the group of persons so exposed are called critical groups. As used here, "critical" denotes the sense of importance relative to other pathways and groups and identifies the pathway(s) that will have to be limited in order to control the dose.

For any given site, only one or a few pathways will prove to be limiting. If the total dose to the public via these limiting pathways is kept below the ICRP recommended dose 1 imits, then the total dose from all pathways combined may be less than the recomenended limit. In addition, although a large number of radionuclides may be released, only a few may contribute significantly to the total dose.

Webb (1980) has listed the items to consider in the analysis of a general pathway model for ocean dumping of radioactive waste, as follows:

- release of radionuclides from the package (container and waste form)

- local mixing with water and adsorption onto sediments

- local biological uptake processes

- physical transport of dissolved or resuspended radionuclides via the water column

- biological transport of radionuclides

- sediment transport

- reconcentration of dissolved radionuciides by biota after transport in water to location of harvest

- exposure of man via ingestion, inhalation and direct irradiation. The estimation of dose to man from ocean disposal of radioactive waste may be carried out using mathematical models describing either transient or steady-state conditions. A third method based upon specific activity is the 
simplest; however, it can only be applied to those radionuclides having stable analogs. The steady-state or concentration-factor approach is only sightiy more complex, but it necessitates that the user assume the system is at equilibrium. On the other hand, the transient or compartmental model methodology, which describes a transient condition produced from a variable source function, is usually more complex and time consuming. Also a knowledge of a great many transfer rates between the various compartments making up the mode 1 is required. In most instances the concentration-factor models are used unless the dynamics or time variation of radionuclides in various compartments is important (ICRP $1980 \mathrm{~b})$.

STEADY-STATE MODELING

The steady-state model or concentration-factor (CF) model contains multiplicative parameters câlied transfer or concentration factors, $F_{i j}$, defined as:

$$
F_{i j}=M_{j}(t) / M_{i}(t)
$$

where $F_{i j}=$ the factor relating concentrations in media $i$ and $j$

$M_{j}(t)=$ activity concentration in compartment $i$ at time $t$

$M_{j}(t)=$ activity concentration in compartment $j$ at time $t$

The factors, $F_{i j}$, are expressed in terms of the units of the $M_{j}$ and $M_{i}$. For example, the concentration factor in SI units that relates fish concentration to that of its surrounding water is in units of $\mathrm{Bq} / \mathrm{kg}$ per $\mathrm{Bq} / \mathrm{m}^{3}$ or $\mathrm{m}^{3} / \mathrm{kg}$.

For equilibrium conditions the concentrations attain constant values so that we can write:

$$
M_{j, e}=M_{i, e} F_{i j}
$$

where the $M_{j, e}$ and $M_{i, e}$ are equilibrium concentrations. 
Dose usually cannot be measured directly because it is lower than the natural background; as a result, the limits are often set for either the radioactive discharge of the practice or the resulting concentrations in air or water. These limits are called "derived limits." When the limits are placed on discharge rate, they must be calculated from the dose limits using any of the modeling techniques and the full critical path. When the limits are placed on environmental concentrations, multiple pathways need not be considered, because they were considered in the setting of the concentration standards.

As mentioned above, for systems that have come to equilibrium or for dynamic systems that may be approximated by a steady-state approach, the use of the concentration-factor model is usually justified. An example of this methodology is presented for calculating the dose, $\mathrm{H}$, (either annual or committed) from the consumption of seafood harvested in waters containing a radionuclide that has been transported from a waste container leaking at a constant rate:

$$
H=R P B U D F \quad \operatorname{rem}(S V)
$$

where $H=$ annual dose, or committed dose over 50 years rem (Sv).

$$
\begin{aligned}
R= & \text { leak rate }(\mathrm{C} i / \mathrm{yr}) \text { or }(\mathrm{Bq} / \mathrm{yr}) \text { of a radionuclide from the waste } \\
\text { container } & \text { hydrospheric dispersion factor } \frac{\mathrm{Ci} / \mathrm{m}^{3}}{\mathrm{Ci} / \mathrm{yr}} \text { or } \frac{\mathrm{Bq} / \mathrm{m}^{3}}{\mathrm{~Bq} / \mathrm{yr}} \\
B= & \text { bioaccumulation factor for seafood } \frac{\mathrm{Ci} / \mathrm{kg}}{\mathrm{Ci} / \mathrm{m}^{3}} \text { or } \frac{\mathrm{Bq} / \mathrm{kg}}{\mathrm{Bq} / \mathrm{m}^{3}} \\
U= & \text { consumption rate of seafood }(\mathrm{kg} / \mathrm{yr}) \\
D F= & \text { dose factor } \frac{\text { rem }}{\mathrm{C} i} \text { or } \frac{\mathrm{Sv}}{\mathrm{Bq}}
\end{aligned}
$$


The calculated dose, $\mathrm{H}$, may be either an annual dose or a committed dose over the period of 50 years. The annual dose is calculated in determining compliance with the ICRP dose limits. The dose factor, DF, is dependent upon the radionuclide involved and the age of the consumer. The collective dose is usuafly calculated by assuming the population is made up entirely of average adults. This is probably satisfactory for calculating collective dose from seafood consumption since in most countries infants and younger children do not consume as much seafood as do adults.

In selecting a disposal site, it is necessary to determine the maximum release rate of radionuclides that would not lead to radiation exposures in excess of the ICRP limits. The above equation then may be rearranged to give a release rate, $R^{\star}$, that should not be exceeded.

$$
R^{*}=\frac{H^{\star}}{P B D D F}
$$

where $H^{\star}=$ the relevant dose 1 imit.

In application, $R$ is usually kept much smaller than $R^{*}$ for any particular nuclide or practice so that the dose limit $\mathrm{H}^{*}$ wil? not be exceeded if the individual is subject to exposure from radionuclides resulting from other operations or practices in addition to ocean disposal.

\section{TRANSIENT MODELING}

A system that is not in equilibrium may, with appropriate approximation, be modeled using concentration factors; however, a more rigorous method is to use a multicompartmental model coupled together by linear first-order equations. This technique, sometimes called the system analysis, SA, method, has been used for the analysis of tracer kinetics in living organisms. See, for example, Whicker and Schultz (1982) and Finkelstein and Carson (1979). It can be extended to dynamically simulate the movement of radionuclides through various media of the environment. These compartments then are connected by various rate constants which determine the relative movement of a radionuclide throughout the system.

The compartments may be highly conceptual, such as the world's surface water or the world's vegetation, or very specific subunits, such as the 
portion of the sea in a small geographic location. The quantity (activity) of a radionuclide is calculated for each compartment at a certain time, and then the whole set of equations governing the system is incremented in units of time such as day, week, month, or year, depending on the rates in the system. Thus, the activity in each compartment will change with each time increment. It is assumed in this type of analysis that after each iteration the activity in each compartment is homogeneously and instantaneously distributed through the compartment such that its concentration is constant throughout the compartment. The larger the compartment and the smaller the time increment, the more questionable this assumption becomes. A great many calculations must be made depending on the number of compartments involved and the number of time iterations.

The general formula for the set of differential equations describing a system of connected compartments with radiological decay is given by:

$$
\frac{d y_{j}}{d t}=\sum_{\substack{i=1 \\ i \neq j}}^{n} k_{i j} y_{i}+P_{j}-y_{j}\left[\sum_{\substack{i=1 \\ i \neq j}}^{n} k_{j i}+\lambda_{j}\right] \quad(j=1,2,3, \ldots n)
$$

where $j$ is the compartment of reference and $i$ designates all other compartments. The $k_{i j}$ and $k_{j i}$ represent the transfer coefficients between compartments having activity inventories of $Y_{i}$ and $Y_{j}$. The first two terms after the equal sign represent all the activity entering compartment $j$ from all other compartments $i$ and from outside the system $P_{j}$. The terms in brackets represent all the activity leaving compartment $j$ and going to all other compartments $i\left(k_{j i}\right)$ and being removed from the system entirely $\left(\lambda_{j}\right)$. The $P_{j}$ includes the source term and ingrowth of daughter radionuclides. The $\lambda_{j}$ includes the radioactive decay constant along with any other removal of concern.

As an example, consider an idealized three-compartment system of a fish existing in a body of water in which radioactive wastes are being released (see Figure 2). It is required to estimate the activity in the fish when activity is being released into the sediment and surrounding water from the waste container at the rates indicated in the figure. Here, $Y_{j}$ represents activity levels in the $i^{\text {th }}$ compartment and $k_{i j}$, the constant fractional rate 


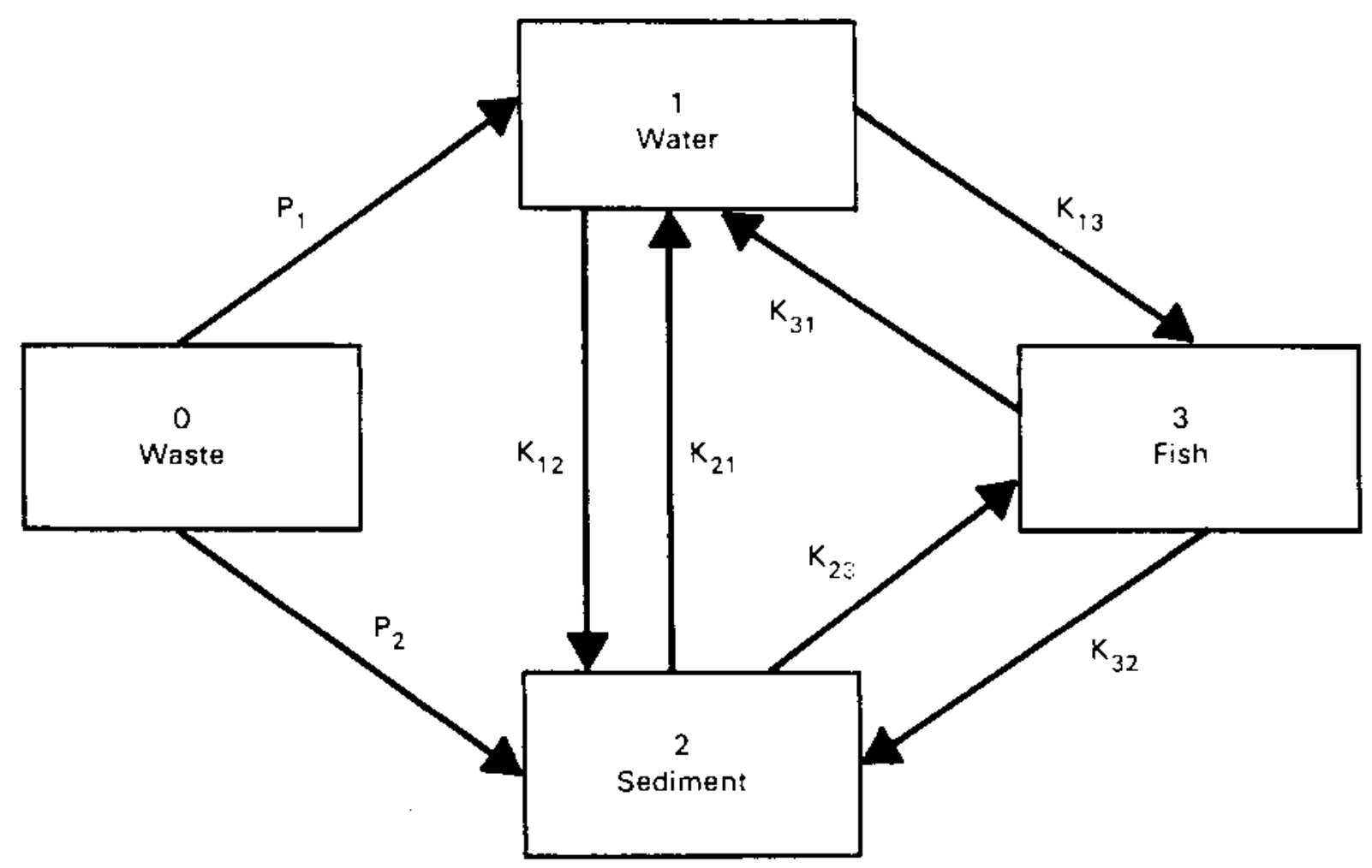

FIGURE 2. Simple Compartment Mode 1

of activity flow in units of reciprocal time from compartment $i$ to compartment $j$. The following set of system equations may immediately be written for this example:

Compartment 1 , Water

$d Y_{1} / d t=K_{21} Y_{2}+K_{31} Y_{3}+P_{1}-Y_{1}\left(K_{12}+K_{13}+\lambda_{r}\right)$

Compartment 2, Sediment

$d Y_{2} / d t=K_{12} Y_{1}+K_{32} Y_{3}+P_{2}-Y_{2}\left(K_{21}+K_{23}+\lambda_{r}\right)$

Compartment 3, Fish

$d Y_{3} / d t=K_{13} Y_{1}+K_{23} Y_{2}-Y_{3}\left(K_{31}+K_{32}+\lambda_{r}\right)$

Here, $P_{1}$ and $P_{2}$ represent the release rate from the waste containers to the water and sediment, respectively. The term for removal from the system is just the radiological decay term $\lambda_{r}$. 
This set of three equations may be solved analyticaliy (Whicker and Schultz 1982); however, for more than about four equations, numerical methods must be used. By converting these equations to difference equations so that a finite change in $t$ will produce a finite change in $Y_{i}$ such that by adding each $\Delta Y_{i}$ to each $Y_{i}$ and then repeating this process for all the equations, the system may be iterated through time until equilibrium is reached $(d Y, d t=0)$.

The resulting compartment activities, $Y_{i}$, may be divided by their respective volumes or masses to determine the concentration of activity in each compartment after any given time period. By decreasing the time increments, $\Delta t$, any degree of precision may be achieved, but only at the cost of increased computational time. However, the degree of numerical precision of the results should never be more than that of the input parameters.

Discussions of compartmental modeling are given in many publications. Good discussions with examples are presented in Publication 29 of the ICRP (ICRP 1980b) and the recent publication by the Organization for Economic Cooperation and Development/Nuclear Energy Agency (OECD/NEA 1980). Hethods for solving these models are summarized in a recent publication for microcomputer users (Hicks 1981).

SPECIFIC ACTIVITY

Whereas the previous two modeling methods are concerned with various pathways, especially the critical pathway, the specific-activity approach is independent of any pathway. The basic assumption in this method is that the specific activity, that is the ratio of the concentration of a radioactive isotope to its stable analog, remains constant throughout all environmental media. Thus by limiting the release of various radionuclides, the specific activity of the recipient medium such as sea water is kept below a fixed value. Thus the specific activity cannot be exceeded at any point in the food chain or in a critical organ in humans (NAS/NRC 1962; IAEA 1978a; Foster, Ophe 1 and Preston 1971). The advantage of this approach is that the requirement for various dilution factors, concentration factors, transfer coefficients, etc. 
is eliminated. The disadvantages of this approach are that some radionuclides (for example, americium and curium) do not have stable analogs; the chemical form of the released radionuclide may differ from its stable analog; and the approach is not applicable for calculating the dose to the GI-tract, since the exposure is produced by the food passing through the gut rather than from deposition in the tissue. However, for some radionuclides such as carbon-14, tritium, iodine-131, and strontium-90 this approach has been useful. However, this approach is not compatible with the methodology in ICRP Publication 26 (ICRP 1977), since the equations and parameters there are based on the intake of the radionuclides irrespective of stable element intake.

\section{MODELING CONSIDERATIONS}

Following the stage of dilution into the immediate receiving water mass, allowance must be made for the factors that influence the amount of a radionuclide actually transferred through successive compartments. Dne important set of factors is geochemical in nature; e.g., distribution coefficients $\left(k_{d} s\right)$ between the water and sea-bed or between water and sedimentary material in suspension. Sediment contaminated by exchange of radionuclides with sea water may be a direct pathway of exposure to man, such as occupaticnal exposure to bottom-fishing gear or recreational occupancy of beaches. In addition, the exchange from sediment to water is important in the consideration of disposal of radioactive waste under the surface of the sea-bed. Modeling of food-chain pathways results in calculated concentrations of radionuclides in food products that are consumed by humans. Once these concentrations are predicted, the intake of radionuclides can be determined from the consumption rates of the food products.

The inverse ratio of the dose (calculated using such models) to the appropriate annual limits of intake (ALI) and external exposure rates recommended by ICRP gives an estimate of the maximum permissible daily discharge rate. The major difference between this method and the "specific-activity" approach lies in the requirement for estimates of the degree of contamination of environmental materials and, more importantly, for detailed information concerning the eating, working and leisure habits from which exposure may ensue in either a local or a more distant population. 
Determining equilibrium concentrations in environmental media and marine organisms using the above pathway approaches provides the starting point for calculations of dose according to methods given in IAEA publications (IAEA 1976, IAEA 1979a).

To ensure that no member of the general public receives exposure in excess of the recommended dose limit, it is necessary to identify the individual or group of individuals who have exceptional habits that lead to the highest potential exposure. The estimated average exposure for this critical group provides the basis on which the permissible release rate is ultimately determined.

\section{SELECTION AND IDENTIFICATION OF PARAMETER VALUES}

The availability of parameter values that support models predicting the transfer of radioactive materials along environmental pathways is likely to be a major influence in deciding the degree of complexity or realism that can be represented by pathway modeling. It is also a major factor in reaching the choice between applying the more fundamentally rigorous transient or systems analysis method or its simplified form--the concentration ratio or steadystate method.

For the transient method, transfer functions are required between compartments that are time-dependent as well as spatially dependent. In the steady-state method, the assumption is made that equilibrium (steady-state) conditions have been attained. Only the ratio of concentrations (or the time integral of concentration) is needed between each pair of compartments assumed to be interacting (e.g., fish vs. sea water). The nature of the parameter values used in the two modeling methods is very different; however, the data needs are similar in the final stage of converting an intake rate of a food-chain materia1, with a calculated activity concentration (or measured dose rate associated with a nonfood-chain pathway) to the dose. For strict application of the transient method, time dependence should be built in. Alternatively, time-averaged values are generally adopted over a period of one year to be consistent with the time base of the ICRP dose limits. 
The values chosen will depend on the type of dose being calculated (individual or collective). In the former case, since the objective will be to investigate conformity with specified dose limits, the choice will generally be that which is characteristic of those people mcst highly exposed through the pathway in question. This topic is addressed in detail in IAEA Safety Series 45 (IAEA 1978a).

Nature of the Released Radioactivity

In addition to the daily or annually released quantities of radioactivity, identified by radionuclide, it is important to know the physical and chemical forms of the radionuclide at the time of release insofar as it may affect its subsequent behavior. For example, studies on plutonium have shown that this element behaves in different ways according to its chemical state or isotopic number (Beasley and Fowler 1976). Additionally, the discharge of the radionuclides in combination with certain nonradioactive wastes may result in complexation or adsorption before mixing with sea water, which could affect its subsequent transport or availability to biological systems.

The proposed method of release, whether continuous, pulsed, or a combination of both, is important since it could define whether the steadystate or transient-analysis approach for dose estimation is appropriate.

\section{Concentration Factors}

When calculating dose, it is obvious that concentration factors (CF) or ratios (CR) for aquatic organisms are required. However, a recommended list of CF values is not readily available because such values are only applicable to specific materials at any one place or time and are subject to continuous revision. While there are many relevant data in the scientific literature, it is necessary to exercise technical judgement in applying them to any one site. It is also possible that if the radionuclide composition of the waste is known in detai1, then assessment of the expected CF values in different materials may be made by stable element analyses obtained from the appropriate literature. Environmentally derived data will generally be most applicable because of the varied use made of such terms as "concentration ratio" or "concentration factor" in experimental studies. Attention should also be paid to 
whether the sea-water values used as a denominator in any CF are based on total water samples (water plus suspended material) or on filtrate water only, and the analytical method by which they were determined.

It is also necessary to consider the degree of accuracy required for parameter values, relative to the calculations being made. A greater accuracy is clearly required for those materials included in the pathway-type calculations that are used to ensure that individual dose limits will not be exceeded. For calculations of collective dose, greater latitude can be tolerated in view of the uncertainties in the size of the population and the pathways of exposure.

\section{Consumption Rates and Occupancy Factors}

In applying the ICRP and national dose limits it is necessary to definitely establish that the dose to the most highly exposed individuals be within those dose limits. In this case, identification of the working, eating, and recreational habits of the local population, and in certain instances a population some distance from the site, may be essential. For example, this might include estimates of marine seafood ingested and the area from which it came, hours spent on the beach at work or as recreation, and hours spent handling fishing gear on the beach and at sea. Consumption rates and occupancy factors derived from surveys of the habits of the identified critical group wiTl be extremely variable. ICRP considers that these sources of variability may appropriately be dealt with by the consideration of dose limits to individuals in this group rather than of an overall dose to the whole group (population dose).

When important pathways cannot be fully identified, potential pathways suspected to be most important, such as consumption of any marine fish species or occupancy of the beach at low tide, should be selected. Following the start of disposal operations, radioactive materials in these assumed pathways should be monitored to provide the basis for their control. 

THE BASIS FOR DEEP-OCEAN DISPOSAL

LONDON DUMPING CONVENTION RECOMMENDATIONS

In contrast to the disposal of liquid wastes to coastal waters, which is under national control, the dumping of packaged radioactive wastes in the deep ocean is specifically governed by the Convention on the Prevention of Marine Pollution by Dumping of Wastes and Other Matter (London Dumping Convention) (IAEA 1974). This convention, which embraces all types of wastes, divides radioactive wastes into two categories: high-level (Annex I) wastes, which are considered unsuitable for dumping in the oceans; and other radioactive wastes, which may be dumped under a national permit (Annex II). The Convention requires the IAEA to define radioactive material that is unsuitable for dumping and to make recommendations that should be considered when issuing national permits. The IAEA prepared a provisional definition for Annex I and recommendations for the Annex II in 1975 (IAEA 1975). This document was subsequently reviewed, revised, issued, and adopted in 1978 (IAEA 1978d). The two key support documents were the Oceanographic Basis (IAEA 1978b) and the Radiological Basis (IAEA 1978C). The definition of HLW took the form of specific activities, which were in turn based on release rate limits; i.e., upper values of release rates for various radionuclides, which, under a series of generally pessimistic pathway parameter values, might give rise to critical group exposure at the ICRP recommended dose 7 imit to the public of $5 \mathrm{mSv}$ $(500 \mathrm{mrem})$. From these studies a revised definition was adopted (IAEA 1978d), which states:

For the purpose of Annex I to the Convention, high-level radioactive wastes or other high-level radioactive matter unsuitable for dumping at sea means any waste or other matter with an activity per unit gross mass (in tonnes) exceeding:

(a) $1 \mathrm{Ci} / \mathrm{t}$ for alpha-emitters but limited to $10^{-1} \mathrm{Ci} / \mathrm{t}$ for ${ }^{226} \mathrm{Ra}$ and supported $210 \mathrm{Po}$;

(b) $10^{2} \mathrm{Ci} / \mathrm{t}$ for beta/gamma-emitters with half-lives of at least 0.5 years (excluding tritium) and beta/gammaemitters of unknown half-lives; and

(c) $10^{6} \mathrm{Ci} / \mathrm{t}$ for tritium and beta/gamma-emitters with halflives of less than 0.5 years. 
The above activity concentrations shall be averaged over a gross mass not exceeding 1000 tonnes.

In a footnote the IAEA goes on to define the upper imits to ocean disposal:

The definition is based on:

(1) An assumed upper 1 imit to the mass dumping rate of 100,000 t per year at a single dumping site; and

(2) Calculated upper 1 imits to activity release rates from all sources (other than natural sources) of

(a) $10^{5} \mathrm{Ci} / \mathrm{yr}$ for alpha-emitters (but limited to $10^{4} \mathrm{Ci} / \mathrm{yr}$ for ${ }^{226 \mathrm{Ra}}$ and supported $210 \mathrm{Po}$;

(b) $10^{7} \mathrm{Ci} / \mathrm{yr}$ for beta/gamma-emitters with half-lives of at least 0.5 years (excluding tritium) and beta/ganma-emitters of unknown half-lives; and

(c) $10^{11} \mathrm{Ci} / \mathrm{yr}$ for tritium and beta/gamma-emitters with half-lives of less than 0.5 years

at a single dumping site and also in the case of aipha-emitters when released to an ocean basin of not less than $10^{17} \mathrm{~m}^{3}$.

Recently the IAEA (1985) proposed a new definition of high-level waste that is under consideration for adoption by the LDC. The new definition considers as high-level waste the irradiated reactor fuel and the 1 iquid wastes from chemical processing of such fuel through the first solvent extraction cycle. Also considered are other wastes having activity levels per unit mass exceeding:

$5 \times 10^{-5} \mathrm{TBq} / \mathrm{kg}\left(1 \times 10^{-3} \mathrm{Ci} / \mathrm{kg}\right)$ for alpha-enitters;

$2 \times 10^{-2} \mathrm{TBq} / \mathrm{kg}(0.5 \mathrm{Cj} / \mathrm{kg})$ for beta/gamma-emitters with half-lives greater than 1 year (excluding tritium); and

$3 \mathrm{TBq} / \mathrm{kg}(80 \mathrm{Ci} / \mathrm{kg})$ for tritium and beta/gamna-emitters with half-lives of 1 year or less.

It is assumed in the definition that the following conditions are satisfied: activity concentrations specified shall be averaged over a gross mass not greater than 1000 tonnes; disposa 1 takes place in an ocean-basin volume of $10^{17} \mathrm{~m}^{3}$; average water depth of site is to be $4000 \mathrm{~m}$; rate of disposal is $10^{8} \mathrm{~kg} / \mathrm{yr}$; disposal continues for $1000 \mathrm{yr}$; and annual dose to members of critical groups shall not exceed I m.Sv (100 mrem). 
When the activity levels per unit mass given in the proposed definition are multiplied by the $10^{8} \mathrm{~kg} / \mathrm{yr}$ disposal rate, it can be seen there is only about a $40 \%$ increase in the alpha-emitters allowed to be disposed of in a year. Also, there is no special reduction for radium-226 and polonium-210. The allowable limit for beta/gamma-emitters has increased 5-fold for those having a long half-life, excluding tritium, and decreased 10 -fold for those with a short half-life, including tritium. The cut-off point between short and long half-life has been increased from $1 / 2$ year to 1 year. Thus, in general, the proposed basis for the definition of high-level waste is Tess restrictive than before.

\section{RADIOLOGICAL EVALUATION OF OCEAN-DISPOSAL PRACTICES}

Need for Modeling

The application of the basic IAEA site selection criteria (IAEA 1978d) effectively minimizes the interaction of the radionuclides from the disposal material with man's activities. This poses a problem both for predicting the potential exposure of populations before the disposal operation and for confirming the estimated exposure following the initiation of disposal operations. Additionally, the quantity of radionuclides relative to the size of the receiving environment, together with such factors as the degree of containment and the time scales involved in transport from the deep ocean, most 1 ikely will result in lower concentrations in potential critical materials than can be measured.

If site-specific radioiogical assessments are required either before the operation is authorized or at intervals thereafter, the lack of confirming data makes validation of the dose exposure estimate from deep-ocean disposal exceedingly difficult. This is in contrast to coastal discharges, where validation of quite simple models can be conducted almost immediately following the initiation of the disposal operations. For the reasons given above, the assessment of deep-ocean disposal will have to rely heavily on mathematical modeling techniques.

Thus, the use of models is central to the assessment of radiation doses from ocean-disposal operations. Models provide the primary means of integrating and interpreting the information gained from other investigations. 


\section{Need for Research}

To apply models, additional deep-ocean scientific research and monitoring will be required to provide realistic parameters that correctly represent the major oceanographic and biological processes of the area in question. However, in view of the ICRP requirement for optimization of radiological protection, which involves consideration of costs and benefits, the research requirements must focus on the needs of the pathway analysis rather than on acquiring a detailed understanding of all the physical and biological transport processes involved within the system.

It should be noted that the term "site specific" does not mean that all investigations must be undertaken at and in the vicinity of a proposed site. It is possibie that the released radionuclides will be transported away from the site, especially the long-lived radionuclides whose half-lives exceed the residence time in the oceans. It is therefore necessary to obtain data on basin-wide circulations, as well as on mixing within the ocean basin. In addition, there is a need to examine those processes that occur on the margins of basins, which have the potential to mix or conduct water from the deep ocean into biologically productive zones.

Four distinct areas of research are required for a coordinated effort: physical transport processes, geochemistry, biological pathways analysis, and model development.

\section{NEA MODEL}

The conceptual framework proposed by OECD/NEA (1981) for evaluation of ocean disposal of radioactive wastes may be represented by a general model that we will call the "NEA Model." The general form of the model is designed to aid in focusing research work and to assist in incorporating the results of research directiy relevant to the preparation of a site-specific assessment of doses resulting from deep-ocean disposal.

The general model envisaged for overall assessment purposes may be divided into three essentially distinct parts: release, marine, and pathway. 
Release Model

The release model describes the release of radionuclides from waste packages; its input is the rate of disposal of wastes and its output the release rate from the package of various radionuclides to sea water or sediments. Past assessments have assumed that disposal of all radionuclides in the ocean are released instantaneously. This is probably a reasonable assumption (except for radionuclides with very short half-lives; e.g., those less than 10 years), and only a small elaboration of this part of the model would be appropriate. A suitable next step might be to use a single compartment model with a flushing time that depends on leach rate from the package and the radionuclide involved and its chemical form, if and when such data become available.

Marine Model

The marine model describes the dispersion and reconcentration of radionuclides throughout the marine environment. Its inputs are the release rates of the various radionuclides and its output the time-dependent concentrations of the various radionuclides throughout the water, sediments, and biota of the ocean. It includes geochemical processes such as sediment/water interactions and biological processes such as scavenging and bioturbation, insofar as they significantly affect the mass transport of radionuciides and therefore the overall concentrations. The concentrations so calculated may be long-term averages or they may include short-term fluctuations. Initially, different dedicated physical models will probably be needed to study these different processes. The marine model is intended to include all processes that significantly affect or determine the radionuclide concentrations in the marine environment. Thus the effects of sedimentation, scavenging by biogenic particles, and transport by marine organisms (if determined to be important through further study) are to be included in this part of the modeling process.

Pathway Model

The pathway model describes the transport of radioactivity through food chains and other direct pathways to man (e.g., external exposure from sediments). Its input is the concentrations in edible marine organisms or 
other materials leading to doses to man that are derived from the marine biota. These transports may be very small in mass transport terms (i.e., they do not perturb the overall concentrations significantly), but they are crucial because they lead directly to man. The food chains may contain several links and may begin with sedentary biota in either deep or shallow water. The concentrations of radionuclides in the marine environment and in biota are necessarily calculated as part of the marine and pathway models and may be used to evaluate doses to marine organisms as well as doses to man.

\section{IAEA MODEL}

The model developed by the International Atomic Energy Agency (IAEA) contains two parts:

1. an oceanographic component that predicts the relationship between water concentration and release rate at a point in the ocean appropriate to the various pathways (IAEA 1978b);

2. a radiological component that takes the results of the oceanographic component and combines them with data on (assumed) environmental exposure pathways and ICRP data to relate human radionuclide intake rates to dose (IAEA 1978C).

Since the IAEA model was proposed, work has been carried out by the GESAMP to provide advice for more suitable modeling techniques. This body, whose full name is the IMO/FAO/UNESCO/WMO/WHO/IAEA/UN/UNEP Joint Group of Experts on the Scientific Aspects of Marine Pollution, has recently released its findings concerning the various models under study, which it felt would reasonably estimate the doses to persons and biota from ocean disposal (IAEA 1983). More recently, from this work, IAEA (1984) has sumarized the modeis and parameter values that they feel would provide an approach to the definition of wastes that are unsuitable for disposal but would not exceed recommended limits. In the paragraphs below, the older model is discussed first and then followed by the later model. 
Oceanographic Component

Present Mode]

The model adopted (IAEA 1978b) was a hybrid of several fairly simple calculations. It was based partly on the conclusions of the work of Shepherd (1976), but it included additional consideration of the possible effects of short-term processes and unusual events. These are particularly important insofar as they may "short-circuit" the steady and progressive deep-ocean dispersion allowed for in the Shepherd model.

The Shepherd model was developed to permit calculation of theoretical equilibrium concentrations in the ocean, both at the surface and in vertical profile, from a continuous release of material on the bottom of the deep ocean. Application of Shepherd's model showed that, except under rather extreme conditions, the surface concentrations given would not exceed the long-term average value that would arise if all the activity released were eventually distributed over the whole ocean. To overcome the possibility that some biological pathways might short-circuit the most obvious pathway to man (via dispersion of activity in the water mass and then via the consumption by man of fish from the surface layer of the continental sheif fishing grounds), the IAEA based their radiological assessment on bottom concentrations as if the (normally higher) bottom concentrations were present in the surface waters. A considerably slower, vertical diffusivity $\left(1 \mathrm{~cm}^{2} / \mathrm{s}\right)$ was used, corresponding in the Shepherd model to a 4000-year vertical mixing time. In addition, it was assumed that release would continue for a period of 40,000 years, which is comparable with the mean lifetime of plutonium-239.

Thus far, these results provided concentrations applicable to an ocean volume of $10^{17} \mathrm{~m}^{3}$ (which is in fact slightly smaller than the true volume of the North Atlantic), irrespective of whether a single site or muttiple sites are used for dumping. While Shepherd's model provided the concentration arising from the long-term, large-scale dispersion from a dump site, it did not include the possibility of physical, chemical or biological processes, which, on time-scales of decades or less, might result in higher concentrations in pathways leading to man. The IAEA oceanographic basis included estimates of such processes that could short-circuit long-tem dispersion 
processes. These were based on the possibility of an advective plume of year-long duration reaching a fishing zone in deep water (e.g., a long-line fishery) and deep convective mixing of the type that has been observed down to about $2000 \mathrm{~m}$ in the Mediterranean Sea and in the polar deep-water formation regions. Calculations that had been carried out for these two cases indicated that the concentration arising in the short term from a single site might be of the order of $10^{-6} \mathrm{Ci} / \mathrm{m}^{3}$ per $\mathrm{Cj} / \mathrm{s}$ released, and this value was therefore used as a more restrictive limit for single sites, except for the longer-lived nuclides, where the whole ocean limit becomes more restrictive.

The oceanographic model also describes disposal of waste in an area where the depths are normally greater than $4000 \mathrm{~m}$. The assumption is usually made that radionuclides are released continuously from the container beginning as soon as the waste reaches the ocean floor. Any delay in the release of activity from the container, once it has reached the bottom of the sea, will reduce the tota? amount of activity released due to decay in the container, but this factor is not included in the model. It is assumis there is a transit time of three years between release from the container and arrival at the nearest possible place of interaction with man, and it is also assumed that continuous release rates prevail.

The oceanographic basis therefore depends on fairty elementary calculations and makes use of several rather sweeping simplifications. These are principally that: 1) the concentrations appropriate for input to food chains in the surface waters are the (higher) concentrations of deep-ocean waters; 2) although sediments are assumed to come to equilibrium with concentrations in water, no activity is actually depleted from the water column onto sediments; and 3) there is an appreciable chance that fluctuations will dominate concentrations in a critical pathway.

All these simplifying assumptions are intended to err on the side of conservatism (tending to overestimate dose). They are in general particularly pessimistic for short-lived radionuclides. For long-lived alpha-emitting wastes (such as plutonium-239), which are of particutar concern, the degree of conservatism is not large, perhaps one or at most two orders of magnitude. The IAEA advisory group, who drew up the revised definition, attempted to 
estimate the possible degree of conservatism; it was published with the radiological basis described in IAEA $1978 \mathrm{c}$.

\section{Proposed Models}

The new models proposed by the GESAMP are somewhat more sophisticated than the older Shepherd model; however, the philosophy is still that the level of sophistication of the models should match what is actually known about the natural processes. The following processes were considered (IAEA 1984):

1) movement and mixing of water within the ocean basin

2) radioactive decay or chemical degradation of contaminants

3) interaction of contaminants with particles of various types both within the water column and on the sea bottom

4) mixing and diffusion including bioturbation in and out of surface sediments.

The GESAMP stressed that the interactions of contaminants with inorganic and organic particles was important in the resulting activity contribution in the water.

Three ranges of distance from the source were to be considered for calculation of activity concentrations: an extreme near-field, an intermediate near-field, and a far-field. Definitions for these terms are given in the glossary.

For the near-field the IAEA chose the models discussed in Appendix VII and Appendix VI of the GESAMP report (IAEA 1983). Model VII is a simple three-dimensional ocean-diffusion model modified for finite source size and scavenging, whereas $V I$ is a one-dimensional model. For the near-field, model VII is to be used in most cases unless it gives a smaller concentration than model VI, in which case model VI should be used. For the extreme near-field, model VII should be used.

The Appendix VII (near-field and extreme near-field) model is summarized below. The radionuclide activity concentration is given by the relation:

$$
c=c^{\prime} \frac{0}{\pi r_{s} \sqrt{K_{H} K_{V}}}
$$


where $Q=$ the rate of release

$$
\begin{aligned}
r_{S}= & \text { the radius of the source } \\
K_{H}, K_{V}= & \text { the horizontal and vertical eddy diffusivity in the water } \\
& \text { column, respectively } \\
C^{\prime}= & \text { three complex functions of parameters which depend on the } \\
& \text { distance from the source. }
\end{aligned}
$$

This model is to be used for most near-field calculations and all extreme near-field calculations. It may be used for some far-field calculations as we? 1 .

The Appendix VI model (far-field) is a simplified equilibrium version of a more complex modeT found in Appendix IX of the GESAMP report. This onedimensional model includes diffusion, boundary scavenging, interior scavenging, and up/down movement of water. A summary of the form of the model is given by the relation for concentration:

$$
c=a e^{r_{1} z}+b e^{r_{2} z}
$$

where $z$ = the vertical distance from the ocean bottom

and $r_{1}, r_{2}=$ the roots of a puadratic equation with coefficients being functions of various oceanographic parameters

$a, b=$ involved functions determined by the surface and bottom boundary conditions.

This model is to be used for far-field and near-field calculations if the results prove higher than the Appendix VII model.

Radiological Component

\section{Present Model}

For the radiological component, the IAEA (1978c) considered doses to critical groups via 12 pathways (see Table 2). Release-rate limits were derived by first calculating the dose to man in each pathway arising from a unit release rate. The method used for this calculation was conventional, combining an estimate of water concentration (from the oceanographic basis), a concentration factor, a consumption or occupancv rate, and the appropriate 
for example, for which the release rate 1 imit is of the same order as the natural production rate; while the natural dose rates from marine radium-226 are known to be much less than the ICRP dose 1imi: (Mitchell and Shepherd 1981).

It should be recognized that the mathematica modeling from which the current IAEA definition was derived is generic in nature. As such, it provides a means by which upper limit values of dose may he estimated. It thus is more likely to lead to overestimates of dose than is one tailored to a specific location or set of conditions.

\section{Proposed Mode1}

The primary changes from the old model of the radiological component have been in the reduction of the disposal period from 400,000 years to 1000 years and changes in pathways and usage rates (IAEA 1984).

The change to 1000 vears for disposal was based on the fact that it more nearly represents a fraction of well-recorded political and social history but only a minute fraction of geological history. Thus, it was thought that no major social or geological changes would have taken place over this time period to invalidate the pathway and usage assumptions.

The new pathway and usages are summarized in Table 3. As can be seen, concern has been expressed for additional future pathways of deep-sea mining and the consumption of deep-sea fish and plankton. The IAEA contended trat. these lest two pathways were only hypothetical and should not be inciuded in the calculation of disposal-rate limits without "careful consideration."

The release-rate limit was then derived as before using the appropriate annual 1 imit of intake (ALI) for internal exposure and appropriate dose iimit for external exposure.

Calculations of this nature are required for actual pathways, except middepth fish and mining using only surface-water concentrations. For mid-depth fish, a depth of $1000 \mathrm{~m}$ was selected for the calculation of concentration. In addition to the calculation, a sensitivity analysis is to be performed to ascertain the importance of various parameters and assumptions. 
TABLE 3. Pathways and Usages Proposed by the IAEA (IAEA 1984)

\begin{tabular}{lr}
\multicolumn{1}{c}{ Pathway } & Usage \\
\cline { 1 - 1 } Actual & \\
\hline$\frac{\text { Ingestion }}{\text { Surface fish }}$ & $300 \mathrm{~g} / \mathrm{d}$ \\
Mid-depth fish & $300 \mathrm{~g} / \mathrm{d}$ \\
Crustacean & $100 \mathrm{~g} / \mathrm{d}$ \\
Mollusc & $100 \mathrm{~g} / \mathrm{d}$ \\
Salt & $3 \mathrm{~g} / \mathrm{d}$ \\
Desalinated sea water & $2 \mathrm{~kg} / \mathrm{d}$ \\
Inhalation & \\
Suspended airborne sediments & $23 \mathrm{~m} / \mathrm{d}$ \\
Marine aerosols & $23 \mathrm{~m} / \mathrm{d}$ \\
External Irradiation & \\
\hline Boating & $5000 \mathrm{hr} / \mathrm{yr}$ \\
Swimming & $300 \mathrm{hr} / \mathrm{yr}$ \\
Beach sediments & $2000 \mathrm{hr} / \mathrm{yr}$ \\
Deep-sea mining (a) & $500 \mathrm{hr} / \mathrm{yr}$
\end{tabular}

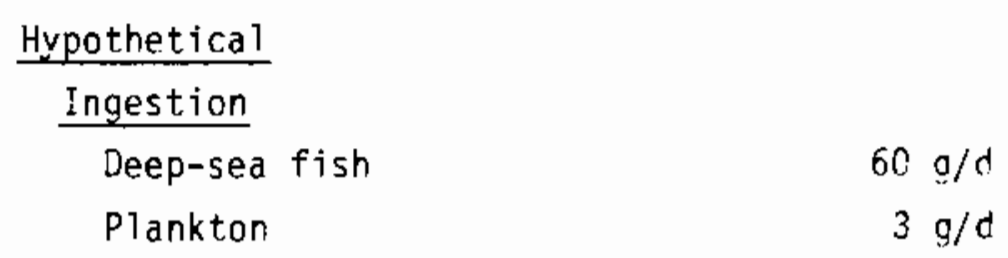

(a) Also inhalation at $23 \mathrm{~m}^{3} / \mathrm{d}$.

It was also proposed that the dose to marine organisms be calculated separately. Both internal and external doses should be calculated to the organism from the spatial distribution of activity predicted by the models including sediment. Then a combination on the effects of these doses on their populations from an ecological point of view should be made. 
PROBLEMS IN THE ASSESSMENT OF OCEAN DISPOSAL OF LOW-LEVEL WASTE

\section{COLLECTIVE DOSE}

In principle, the acceptable risk level associated with a practice such as ocean disposal should be examined through a cost/benefit analysis, based on the principle of optimization (ALARA). The detriments from the use of nuclear energy are best expressed as a collective dose equivalent in order to permit a meaningful cost/benefit analysis to be performed. An optimization derived from a cost/benefit analysis should be translatable to guidance on allowable disposal rates, although resulting regulations may or may not define limitations on the collective committed dose.

At present, there are no specific regulations in the United States that address quantitative limitations on collective dose. In the past, the former Atomic Energy Commission (AEC) and the EPA had given some thought to such Iimitations for populations around light-water reactors, but no formal regulations were ever issued. The recent EPA regulation for geologic disposal of high-level wastes (40 CFR 191) does contain limits on releases of radionuclides from a repository to the "accessible environment" that were derived from a consideration of the potential health effects to the population exposed to such releases. These health effects were considered to be proportional to collective dose in the EPA system of radiological assessment, which uses the linear, nonthreshold assumption.

Regardless of whether the best approach is to define the basic limits in terms of collective dose or nuclide releases, there remains the requirement to translate the limit into usable terms, such as allowable quantities of radionuclides per container, allowable annual quantity to be disposed, and/or total allowable quantity disposed per site.

Granted that the calculation of some type of collective dose is warranted, the question remains as to what type should be calculated. It is possible to evaluate a "collective committed dose," wherein an acute or chronic external exposure and radionuclide intake are used to derive a total dose accrued over some time longer than the standard IAEA exposure period of 50 years. 
It also is possible to evaluate the "collective dose comnitment," accrued by one or severa? generations of people, that results from the long-term exposure to radionuclides present in the environment over the entire exposure period as a result of the practice of ocean disposal. The latter is preferred by some experts because it is an indication of the total potential detriment from a practice and not the detriment from just a single release or an annual release. The collective dose commitment has been used previously by the EPA in the calculation of its "environmental dose" and potential health effects from nuclear power facilities (U.S. EPA 1974). A further decision is needed on the length of time over which the population detriment should be evaluated: hundreds, thousands, or tens of thousands of years.

\section{CHOICE OF A RADIOLOGICAL PROTECTION SYSTEM}

Because the potential detriment to the United States (or the world) population could arise from wastes disposed of by more than one national authority, it is desirable that the systems of radiological assessment that are employed by each be compatible. Such compatibility ensures that the detriments calculated by each national authority for its waste disposal practice are capable of being translated to a common basis for summation or comparison with those of other national authorities.

Radiation dose can be calculated using any of several systems providing radiological guidance. For example, an organ or whole-body dose can be calculated using the equations given in ICRP Publication 2 (ICRP 1959) and then summed over a population group. This has been the past practice in the United States, even though over the years certain improvements have been incorporated. These include the new ICRP task group lung model (ICRP 1972) and multiple exponential radionuclide retention in the body and in individual organs (ICRP 1968).

The advantages of the system described in ICRP Publication 2 include simplicity of the dosimetry equations [compared to those in ICRP Publication 26 (ICRP 1977)], and familiarity of those in the health physics profession with its interpretation and application. Last, but not least, is the fact that the maximum pernissible concentrations (MPC) in air and water derived under this system have already been incorporated into federal regulations in several countries including the linited States (10 CFR 20). 
This may prove to be a disadvantage, however, because the changes and improvements in metabolic parameters that enter into the calculations of dose are not usually reflected in a convenient and timely fashion by the MPC values that are published in the codes of Federal Regulations.

Collective doses can also be calculated using the radiological protection system defined in ICRP Publication 26 (ICRP 1977), where in an "effective" (weighted) whole-body dose is calculated as explained in earlier sections of this report. This system is based on a desire to limit total risk of health detriment to all exposed organs of the body. It attempts to arrive at a single weighted value for an "effective" whole-body dose. One advantage of this system is that it obviates the need to compound potential health effects in each of several organs after the individual organ doses are calculated.

There has been considerable discussion on the problems of implementing the "ICRP-26" system; these probTems may not be apparent to those not intimately familiar with the state-of-the-art in internal dosimetry and the availability (or rather the lack thereof) of metabolic parameters necessary to use the "effective" whole-body dose concept (Thompson 1979). One principal problem arises from the fact that uptake and elimination parameters for most radionuclides are available for only a few of the organs for which ICRP has assigned values of the weighting fraction, $W_{T}$. In addition, such data are generally only available for the few organs that tend to have the highest concentrations and for the whole body. The way around the lack of data was to simply assume that all of the radionuclides not accounted for by the known deposition parameters are uniformly distributed throughout the remainder of the body mass. The mass, in this case, is the difference between $70 \mathrm{~kg}$ and the mass of the organs having a known deposition. This was all that could be done, short of delaying implementation of the system for many years, while many mitlions of dollars were spent on animal research designed to define the missing data.

Another disadvantage of the method in ICRP-26, at least in theory, is that the correct intake limits based on a "weighted" whole-bcdy dose for each nuclide should not be calculated independently of the other nuclides present in a mixture, as outiined in the methodology. Since the formula involves 
terms for summation of dose to the "next five highest" exposed organs, the sumation of dose to all organs from all nuclides present should be calculated before one decides which five organs receive the highest exposure.

It is doubtful that the extreme complexity introduced by the new system is warranted by the accuracy of the results. In addition, the technique of spreading the "remaining" body activity over the "remaining" body mass tends to create effective dose factors that are heavily dependent on the few "known" organs (or in some cases a single critical organ). As it now stands, the major differences between the radionuclide intake limits in ICRP-2 (1959) and ICRP-26 (1977) often result from revisions to metabolic parameters.

The potential differences that might arise when different radiation protection systems are used to derive ocean-disposal guidance are explored for nine radionuclides of interest in other than high-level (OTHL) wastes. The comparisons were actually made between maximum permissible rates of intake (MPRI) by ingestion based on the methodology in ICRP-2 and variations thereof, and the annual limit of intake (ALI), which was derived from ICRP-26 methodoiogy and published in several parts of ICRP Publication 30 and the supplements thereto (ICRP 1979a, 1979b, 1980a, 1981a, 1981b, 1982a, 1982b). The calculated MPRI and ALI values were expressed as those assumed to be appropriate for an individual adult member of the general public (i.e., one-tenth of those for persons occupationally exposed for 168 hours/wk). The results of the comparisons are shown in Table 4.

The comparisons are not completely straightforward in all cases, as evidenced by the large number of footnotes for the table. Besides changing the basis for deriving the ALI, as compared to the former MPRI (MPC) values, there have been several changes in metabolic models and parameters and in values of quality factors (Q). The values of the ratios (ALI/MPRI) furthest from 1.0 can be traced in part to these changes.

For example, the metabolic model for ${ }^{90} \mathrm{Sr}$ has changed since the publication of ICRP-2 from a single exponential to a multiple exponential and then to a combination of multiple exponentials plus a power function. In the process, the value of the parameter $\left(f_{1}\right)$ for uptake from the GI-LLI to biood has been 
TABLE 4. Comparison of Allowable Intake by Individual Members of the PubTic for Selected Radionuclides

\begin{tabular}{|c|c|c|c|c|c|c|c|}
\hline \multirow[b]{2}{*}{ Nuclide } & \multicolumn{3}{|c|}{ MPRI (Bg/yr) } & \multirow{2}{*}{$\frac{\mathrm{ALI}(\mathrm{Bg} / \mathrm{yr})^{(\mathrm{i})}}{\mid \mathrm{CRP}-30}$} & \multicolumn{3}{|c|}{ Ratio ALI/MPR! } \\
\hline & ICRP-2 $^{\text {(a) }}$ & 10 CFR 20 ${ }^{(\mathrm{a})}$ & $\begin{array}{l}\text { Fic Dosp } \\
\text { Limits }\end{array}$ & & ICRP-2 & 10 CFR 20 & FRC \\
\hline $3_{H}$ & $3 E \theta^{(c)}$ & $97^{(d)}$ & $3 \mathrm{~EB}$ & 3E8 & 1 & 3 & 1 \\
\hline${ }^{60} \mathrm{Co}$ & $1.5 \mathrm{E} 6$ & $1.5 E 6$ & $1.4 \mathrm{E} 6$ & $7 \mathrm{ES}$ & 0.5 & 0.5 & 0.5 \\
\hline${ }^{90} \mathrm{Sr}$ & $1 E_{4}$ & 9E3 & $6 \mathrm{E}_{3}$ & $1 \mathrm{ES}$ & 10 & 10 & 20 \\
\hline${ }^{106} \mathrm{Ru}$ & 3E5 & 3E5 & 3E5 & 7E5 & 2 & 2 & 2 \\
\hline 129 l & $1 E_{4}$ & $2 E 3^{(e)}$ & BE3 & $2 \mathrm{E} 4$ & 2 & 10 & 3 \\
\hline${ }^{137} \mathrm{Cs}_{5}$ & 6E5 & 6E5 & $3 E 5$ & 4E5 & 0.7 & 0.7 & 1 \\
\hline${ }^{144} \mathrm{Ce}$ & $3 \mathrm{E} 6$ & 3E5 & $3 E 5$ & BES & 3 & 3 & 3 \\
\hline${ }^{226} \mathrm{Ra}$ & $3 \mathrm{E}_{2}$ & 9E2 & 8E1 & $7 E 3$ & 20 & 8 & 80 \\
\hline${ }^{239} \mathrm{Pu}$ & $\begin{array}{l}2 E 5^{(f)} \\
2 E 5^{(g)}\end{array}$ & $2 \mathrm{E5}$ & $\begin{array}{l}7 E 4^{(f)} \\
1 E 5^{(h)}\end{array}$ & $2 E_{4}$ & $\begin{array}{c}0.1 \\
\{0.1\rangle\end{array}$ & $\begin{array}{c}0.1 \\
(0.2)\end{array}$ & 0.3 \\
\hline
\end{tabular}

(a) Calculated by multiplying most restrictive 168-hr MPC (public) by annuol mater intake,

(b) Calculated by dividing the FRC dose limft for individlol organs by the corresponding values of dose-per-unit intake calculated as in Hoenes and Soldat (1977) with metabolic parameters updated through ICRP Publication 19 (ICRP 1972).

(c) Caiculated for tole body and $0=1.0$.

(d) Based on body water and $Q=1.7$.

(e) The MPC volues for iodine in 10 CFR 20 are based on a 2-gram thyroid, a fluid intake of $1 \mathrm{~L} / \mathrm{d}$ and an annual dose 1 imit of $1.5 \mathrm{rem} / \mathrm{yr}(15 \mathrm{mSv} / \mathrm{yr})$.

(f) Based on parameters in 1CRP-2, with bone as critical organ.

(g) Based on parameters in 1CRP-19, with liver as critical organ.

(h) Based on parameters in ICRP-19, with bone as critical organ.

(i) The values listed are one-tenth of the most restrictive occupational ALI value for the corresponding nuclide.

changed, and the value of the biological half-life recomended for the single exponential model has also been changed. The ratio of ALI to U.S. Federal Radiation Council (FRC) MPRI is 20 rather than 10 because the FRC dose limit is $1.5 \mathrm{rem} / \mathrm{yr}(15 \mathrm{mSv} / \mathrm{yr})$ to bone as opposed to the $3.0 \mathrm{rem} / \mathrm{yr}(30 \mathrm{mSv} / \mathrm{yr})$ recommended in ICRP-2 and used as the basis for the MPC values in 10 CFR 20 .

The ratios for ${ }^{239} \mathrm{Pu}$ are complicated by the change in the value of $Q$ for alpha emitters from $10($ ICRP-2) to 20 (ICRP-30). In addition, the introduction of new values for distribution of $\mathrm{Pu}$ in the body in ICRP Publication 19 (ICRP 1972) changed the critical organ from bone to liver. For the ICRP-2 corrected values (see footnote $g$ of Table 4), this also meant a shift from a dose limit of $3 \mathrm{rem} / \mathrm{yr}(30 \mathrm{mSv} / \mathrm{yr}$ ) to bone to $1.5 \mathrm{rem} / \mathrm{yr}$ ( $15 \mathrm{mSv} / \mathrm{yr}$ ) to 1 iver. 
The net resuit was that no significant difference appeared in the w.PRI calculated via ICRP-2 methodology, whether based on ICPP-2 parameters for bone or ICRP-19 parameters for Tiver. The values listed under FRC dose limits for ${ }^{239} \mathrm{Pu}$ are lower than ICRP-2 and 10 CFR 20 because of the lower FRC bone 1 imit of $1.5 \mathrm{rem} / \mathrm{yr}(15 \mathrm{mSv} / \mathrm{yr})$.

This discussion is meant to illustrate the extreme complexity involved in the different systems of radiological protection and to illustrate the probleris involved in trying to compare calculated doses or allowable rates of intake of one scheme with those calculated in another scheme.

However, even with the problems discussed above, the ICRP-26 methodology has been accepted by NCRP and is expected to be implemented by the EPA and DOE in the near future. 


\section{CONCLUSIONS}

It should be recognized that until such time as essential data on key oceanographic and biological processes become available, assessments of the impact of ocean dumping will continue to require the application of simplifying but intentionally conservative assumptions. These assessments are designed to provide upper-limit or pessimistic values rather than more realistic values, which would be desired. It will not be possible to determine more realistic values for radiation doses until the concentrations of radionuclides are determined in the materiais in the critical pathways. Nevertheless, the present modeis, which should continue to be improved as the research data becomes available, do provide an adequate basis for regulatory authorities to decide whether authorization for a proposed disposal can be granted, because they provide a means of indicating whether maximum individual (critical group) exposure limits are likely to be exceeded.

In order to implement the ICRP principle of optinization, the collective dose commitment (i.e., the total dose received by the exposed population) must be estimated. The method of estimation usually involves a step-wise summation of a series of calculated committed doses. For the long-lived radionuclides, the assumption of a we1i-mixed ocean requires that the global population, or some portion of it, be considered the exposed population. It is then relatively straightforward, given the total annual production of foods from all or part of the oceans, to estimate the collective amount of activity ingested as well as the dose. For shorter-lived radionuclides, the oceanographic dispersion models presently do not provide sufficient spatial resolution to identify the geographical radionuclide distributions that are necessary to successfully identify the exposed population. Because any values derived are likely to be over-estimates, perhaps by many orders of magnitude, they will provide only a crude basis for the precise assessment of collective dose commitments or for application of quantified optimization procedures. Optinization will, therefore, still have to be decided in a qualitative way by applying value judgments. However, new models and information are continuously being developed 
by the international community to assess ocean disposal of radioactive waste in comparison to land disposal and in the comparison of one site against another. Characterization of each site under consideration for possible disposal (both land and ocean) must be done through modeling, which must include scenarios designed to include conservative yet realistic exposure pathways. 


\section{REFERENCES}

Eeasiey T. M., and S. W. Fowler. 1976. Plutonium and Americium Uptake from Sediment by Polychaete Horms. IAEA-187, IAEA, Monaco.

Finkelstein, L., and E. R. Carson. 1979. Mathematical Modeling of Dynamic Biologicai Systems. Research Studies Press, Forrest Grove, Oregon.

Foster, R. F., I. L. Ophe1 and A. Preston, 1971. "Evaluation of Human Radiation Exposure." In Radioactivity in the Marine Environment, National Academy of Sciences, Washington, D.C.

Hicks, R. E. 1981. "Mathematical Modeling: A BASIC Program to Simuiate Real World Systems." BYTE, June 1981, Vol. 6, No. 6, McGraw Hill, Peterborough, New Hampshire.

Hoenes, G. R., and J. K. Soldat, 1977. Age-Specific Radiation Dose Comnitment Factors for a One-Year Chronic Intake. NUREG-0172, U.S. Nucjeãr Regulatory Commission, Washington, O.C.

Internationa 1 Atomic Energy Agency (IAEA). 1974. Convention on the Prevention of Marine Pollution by Dumping of Wastes and Other Matter. INFCIRC/205, IAEA, Vienna.

International Atomic Energy Agency (IAEA). 1975. Convention on the Prevention of Marine Poliution by Dumping of Wastes and other Matter. The Uefinition Required by Annex 1 , Paragraph 6 , to the Convention, and the Recommendations Required by Annex II, Section D. INFCIRC/205/Add I IAEA, Vienna.

International Atomic Energy Agency (IAEA). 1976. Effects of Ionizing Radiation on Aquatic Organisms and Ecosystems. Tech. Rpt. Series, No. 172, TAEA, Vierna.

International Atomic Energy Agency (IAEA). 1978a. Principles for Establishing Limits for the Release of Radioactive Materials into the Environment. Safety Series No. 45, TAEA, Vienna.

International Atomic Energy Agency (IAEA). 1978b. The Oceanographic Basis of the IAEA Revised Definition and Recommendations Concerning Tigh-Level Radioactive Waste Unsuitable for bumping at Sea. IAEA-TECDOC-210, IAEA, Vienna.

International Atomic Energy Agency (IAEA). 1978c. The Radiological Basis of the IAEA Revised Definition and Recommendations Concerning High-LeveT Radioactive Waste Unsuitable for Dumping at Sea. IAEA-TECLCC-211, IAEA, Vienna. 
International Atomic Energy Agency (IAEA). 1978d. Convention on the Prevention of Marine Pollution by Dumping of Wastes and Other Matter. The Definition Required by Annex I, Paragraph 6, to the Convention, and the Recommendations Required by Annex II, Section D. INFCIRC/205/Add 1/Rev. 1, IAEA, Vienna.

International Atomic Energy Agency (IAEA). 1979a. Methodology for Assessing Impacts of Radioactivity on Aquatic Ecosystems. Tech. Report Series No. 190, IAEA, Vienna.

International Atomic Energy Agency (IAEA). 1979b. Application of the Dose Limitation System for Radiation Protection, Practical Implications. Proceedings Series, IAEA, Vienna.

International Atomic Energy Agency (IAEA). 1983. IMO/FAO/UNESCO/WMO/WHO/ IAEA/UN/UNEP Joint Group of Experts on the Scientific Aspects of Marine Pollution-GESAMP. An Oceanographic Model for the Dispersion of Wastes Disposed of in the Deepsea. Reports and Studies No. 19, IAEA, Vienna.

International Atomic Energy Agency (IAEA). 1984. The Oceanographic and Radiological Basis for the Definition of High-Level Wastes Unsujtable for Dumping at Sea. Safety Series No. 66, IAEA, Vienna.

International Atomic Energy Agency (IAEA). 1985. The Definition Required by Annex I, Paragraph 6 to the Convention, and the Recomendations Reguired by Annex I, Section 0. Final Draft. INFCIRC/205/Add. 1/Rev. 2, IAEA, Vienna.

International Commission on Radiological Protection (ICRP). 1959. Recommendations of the International Commission on Radiological Protection. ICRP Publication 2, Pergamon Press, Oxford.

International Commission on Radiological Protection (ICRP). 1965. Recommendations of the International Commission on Radiological Protection. ICRP Publication 9, Pergamon Press, 0xford.

International Commission on Radiological Protection (ICRP). 1968. Evaluation of Radjation Doses to Body Tissues from Internal Contamination due to Occupational Exposure. ICRP Publication 10, Pergamon Press, oxford.

International Commission on Radiological Protection (ICRP). 1972. The Metabolism of Compounds of Plutonium and Other Actinides. ICRP Publication 19, Pergamon Press, New York.

International Comission on Radiological Protection (ICRP). 1973. Imp]ications of Commission Recomnendations that Doses be Kept as Low as Readily Achievable. ICRP Publication 22, Pergamon Press, Oxford.

International Commission on Radiological Protection (ICRP). 1977. Recommendations of the International Commission on Radiological Protection. ICRP Publication 26, Pergamon Press, oxford. 
International Comrission on Radiological Protection (ICRP). 1979a. Limits for Intakes of Radionuclides by Workers. ICRP Publication 30, Part 1, Pergamon Press, New York. Also Annals of the ICRP, 2(3-4), 1979.

International Commission on Radiological Protection (ICRP). 1979b. Limits for Intakes of Radionuclides by Workers. ICRP Publication 30, Supplement to Part 1. Also Annals of the ICRP, 3(1-4), 1979.

International Commission on Radiological Protection (ICRP). 1980a. Limits for Intakes of Radionuclides by Workers. ICRP Publication 30, Part 2 , Pergamon Press, New York. ATso Annals of the ICRP, 4(3-4). 1980.

International Cormission on Radiological Protection (ICRP). 1980b. Radionuclide Release into the Environment: Assessment of Doses to Man. ICRP Publication 29, Pergamon Press, New York.

International Commission on Radiological Protection (ICRP). 1981a. Limits for Intakes of Radionuclides by Workers. ICRP Publication 30, Supplement to Part 2, Pergamon Press, New York. ATso Annals of the ICRP, 5(1-6), 1981.

International Commission on Radiological Protection (ICRP). 1981b. Limits for Intakes of Padionuclides by Workers. ICRP Publication 30, Part 3 , including addendum to Parts 1 and 2, Pergamon Press, New York. Also Annals of the ICRP $, 6(2-3), 1981$.

International Commission on Radiological Protection (ICRP). 1982a. Limits for Intakes of Radionuclides by Workers. ICRP Publication 30, Supplement A to Part 3, Pergamon Press, New York. Also Annals of the ICRP, 7(1-3), 1982.

International Comission on Radiological Protection (ICRP). 1982b. Limits for Intakes of Radionuclides by Workers. ICRP Publication 30, Supplement B to Part 3, including addendum to the supplements of Parts 1 and 2, Pergamon Press, New York. ATso Annals of ICRP, 8(1-3), 1982.

Mitche11, N. T. and J. G. Shepherd. 1981. "The UK disposal of solid radioactive waste into the Atlantic Ocean and its environmental impact." In Environmental Impact of Nuclear Power. British Nuclear Society, London.

National Academy of Sciences/National Research Council (NAS/NRC). 1962. Disposal of Low-Level Radioactive Waste into Pacific Coastal Waters. Pub. 985 NAS/NRC Washington, D.C.

National Council on Radiological Protection and Measurements (NCRP). 1975. Review of the Current State of Radiation Protection Philosophy. Report No. 43, Washington, D.C.

Organization for Economic Cooperation and Development/Nuclear Energy Agency (OECD/NEA). 1980. Review of the Continued Suitability of the Dumping Site for Radioactive Waste in the North-East Atlantic. OECD/NEA, Paris. 
Organization for Economic Cooperation and Development/Nuclear Energy Agency (OECD/NEA). 1981. Agency Research and Environmental Surveillance Program Related to Sea Disposal of Radioactive Waste. OECD/NEA Paris.

Shepherd, J. G. 1976. "A Simple Model for the Dispersion of Radioactive Wastes Dumped on the Deep Seabed." Fish. Res. Tech. Rep., No. 29. Ministry of Agriculture, Food and Fisheries, UR.

Thompson, R. C. 1979. "A Consideration of the Wider Impact of Present Trends in Radiation Protection Systems." In Proceedings of a Topical Seminar on the Practical Limitations of the ICRP Recommendations (1977) and the Revised IAEA Basic Standards for Radiation Protection, pp. 629-637. International Atomic Energy Agency (IAEA), Vienna, Austria 5-9, March 1979.

U.S. Code of Federal Regulations (CFR). Title 10, Part 20, "Standards for Protection Against Radiation."

U.S. Code of Federal ReguTations (CFR). Title 40, Part 190, "Environmenta) Radiation Standards for Nuc Tear Power Operation."

U.S. Code of Federal Regulations (CFR). Title 40, Part 191, "Environmental Standards for the Management and Disposal of Spent Nuclear Fuel, High-Level and Transuranic Radioactive Wastes."

U.S. Environmental Protection Agency (EPA). 1974. Environmental Radiation Dose Commitment: An Application to the Nuclear Power Industry. EPA-5?07 4-73-002, U.S. EPA, Washington, 0.C.

U.S. Federal Radiation Council (FRC). 1960. Background Material for the Development of Radiation Protection Standards. Staff Report No. 1, Washington, D.C.

U.S. Federal Radiation Council (FRC). 1961. Background Material for the Development of Radiation Protection Standards. Staff Report No. ?, Washington, D.C.

Webb, G. A. M. 1980. "The Interaction Between Radiological Assessments and Research Requirements Related to Waste Disposal in the Deepsea." In Proceedings of the Third NEA Seminar on Marine Radioecology. Nuclear Energy Agency, Paris.

Whicker, F.W, and V. Schultz. 1982. Radioecology: Nuclear Energy and the Environment, Vol. II. CRC Press, Inc., Boca Raton, Florida.

World Health Organization (WHO). 1978. Health Implications of Nuclear Power Production. WHO Regional Publications European Series No. 3, Copenhagen. 